NBER WORKING PAPER SERIES

\title{
EFFECTS OF SCHOOL SHOOTINGS ON RISKY BEHAVIOR, HEALTH AND HUMAN CAPITAL
}

\author{
Partha Deb \\ Anjelica Gangaram \\ Working Paper 28634 \\ http://www.nber.org/papers/w28634
NATIONAL BUREAU OF ECONOMIC RESEARCH
1050 Massachusetts Avenue
Cambridge, MA 02138
April 2021, Revised March 2023

We thank Michael Grossman, Paige Nong, and Hannes Schwandt for their helpful comments, and Phillip Levine, Sara Markowitz, Edward C. Norton, and Susan T. Parker for substantive suggestions, that improved the quality of this paper. The authors have no external funding or relevant financial relationships to disclose. The views expressed herein are those of the authors and do not necessarily reflect the views of the National Bureau of Economic Research.

NBER working papers are circulated for discussion and comment purposes. They have not been peer-reviewed or been subject to the review by the NBER Board of Directors that accompanies official NBER publications.

(C) 2021 by Partha Deb and Anjelica Gangaram. All rights reserved. Short sections of text, not to exceed two paragraphs, may be quoted without explicit permission provided that full credit, including (C) notice, is given to the source. 
Effects of School Shootings on Risky Behavior, Health and Human Capital

Partha Deb and Anjelica Gangaram

NBER Working Paper No. 28634

April 2021, Revised March 2023

JEL No. I12,I18,I21,J21

\title{
ABSTRACT
}

We examine the effect of school shootings on health and human capital outcomes of exposed students as adults and on their migration during high school and a few years beyond. The analytic dataset use shootings compiled by the Center for Homeland Defense and Security with 2003-2012 Behavioral Risk Factor Surveillance System data. To study migration, we use the 2004-2018 American Community Survey. We find that students exposed to school shootings experience declines in health and well-being, engage in more risky behaviors, and have worse education and labor market outcomes as young adults. There is no evidence of migration in response to school shootings.

\author{
Partha Deb \\ Hunter College \\ Department of Economics \\ 695 Park Avenue \\ Room 1524 West \\ New York, NY 10065 \\ and NBER \\ partha.deb@hunter.cuny.edu \\ Anjelica Gangaram \\ University of Michigan \\ 1415 Washington Heights \\ Ann Arbor, MI 48109 \\ agangara@umich.edu
}




\section{Introduction}

"Toxic stress results from intense adverse experiences that may be sustained over a long period of time - weeks, months or even years" (Middlebrooks and Audage, 2008). Stress during early adulthood has been shown to negatively affect health later in life (Grossman et al., 2018). School shootings are, arguably, "intense adverse experiences" and the stress they create may have long lasting effects. In the United States, school shootings occur regularly, albeit plausibly, randomly across geographic locations. The Washington Post reports that 228,000 students (as of May 8, 2019) have lived through a school shooting since the 1999 shooting at Columbine High School (Cox et al., 2019). However, the effects are likely to extend beyond those directly affected. "Much of the cost is not directly linked to actual victims; it is the anticipation of victimization that engenders widespread anxiety, disinvestment in impacted communities, and costly efforts to avoid and mitigate attacks[;] ... shootings in schools ... are far more important than they appear in victimization statistics" (Cook, 2020). Orcutt et al. (2014) conclude that, "although higher levels of exposure are associated with greater distress, the extant research suggests that even low-level exposure results in widespread significant distress after a shooting." Low level exposure is typically experienced by children in nearby schools, plausibly throughout the school district of the directly affected school. For example, "across the Broward County School district, where Parkland is located, incidents of drug use or possession grew from 511 incidents the previous year to 637 that school year. "'Other major offenses' grew from 317 to 367. Physical attacks grew from 34 the previous year to 128. Threats and intimidation grew to 368 incidents compared to 337 the previous year and tobacco offenses to 439 from 127" (Gaudiano, 2019).

In this paper, we examine the effects of school shootings on the health, health-related behavior and human capital outcomes of exposed middle and high school students as adults in their twenties and early thirties in the contiguous United States. We also study the effect of school shootings on the out-migration of children and young adults.

Our paper contributes to the literature on the effect of shooting related violence on the public more broadly, similar to the work done by Bor et al. (2018) and Ang (2021), in addition to the growing body of literature on school shootings. Recent analyses by Rossin-Slater et al. 
(2020), Cabral et al. (2020), and Levine and McKnight (2020) examine proximate, near-term effects of school shootings. Bharadwaj et al. (2021) examines the effects of a unique mass shooting in Norway on exposed children in both the short and medium term.

We use a comprehensive set of measures meant to study medium term effects, 6-18 years after school shooting incidents. We believe that the results in this paper are the first reported estimates of the medium term effects of school shootings in the US. The study design and our comprehensive analysis suggests that the estimates can plausibly be interpreted as being causal. Therefore, our findings have important implications for public health policy in local areas following school shooting incidents.

We use the 2003-2012 years of the Behavioral Risk Factors Surveillance System (BRFSS) surveys as the source for health, human capital and demographic characteristics at the individual-level (Centers for Disease Control and Prevention, 2019). We restrict the sample to individuals 23 to 32 years of age. An individual is defined as being exposed to a school shooting incident if they live in a county where a school shooting occurred and if they were between 11 and 17 years old during the year of the shooting. All other 23 to 32 old BRFSS respondents living in that county are defined as unexposed. In addition, all 23 to 32 old BRFSS respondents who live in counties that did not face school shootings are defined as unexposed. The treatment variable takes the value of zero if the individual was not exposed and is equal to the number of casualties (injured or killed) in that incident if the individual is exposed to a shooting incident. We examine the effects of exposure to a school shooting on a number of health, health-related behaviors, human capital and labor market outcomes.

We use the 2004-2018 years of the American Community Survey (ACS) to examine the effect of school shootings on migration. We conduct two analyses, one analysis using individuals between 12-18 years old and another using individuals 19-23 years old. We estimate regressions using counties and Public Use Microdata Areas (PUMAs) as our geographic units. Although the analyses that uses county identifiers is consistent with our analyses using BRFSS data, county identifiers are not available for a substantial fraction of ACS respondents. Therefore, we also conduct analyses using PUMAs, as the geographic unit, which are available for all ACS respondents. A 12-18 year old respondent is considered exposed to a school shooting incident if they live in a county (or PUMA) where a school shooting 
occurred 1-4 years ago. For the sample of 19-23 year olds, exposure is defined as an incident in the county (PUMA) of residence 2-8 years ago.

The data on school shooting incidents is from the K-12 School Shooting Database (K12SSD), compiled by the Center for Homeland Defense and Security (CHDS) at the Naval Postgraduate School (Riedman and O’Neill, 2019). According to Riedman and O'Neill (2020), the data collection attempted to include "[each and every instance] a gun is brandished, is fired, or a bullet hits on school property for any reason, regardless of the number of victims (including zero), time, day of week, or reason [e.g. planned attack, accidental, domestic violence, gangrelated, officer involved shooting]." The incidents in the school shootings dataset span the period from 1970 to 2018 and through 2019 up to the date of retrieval. For our analysis of BRFSS data, we use incidents from 1994 to 2005 occurring in middle and high schools. For our analysis of ACS data, we use incidents from 1996 to 2017 occurring in middle and high schools.

We find substantial evidence of declines in health and well-being, worse health-related behaviors and worse education and labor market outcomes. The results remain qualitatively unchanged when plausible, alternative definitions of exposure and intensity of incidents are considered. They are robust to alternative definitions of exposure, the composition of counties in our analysis, the time period of data we chose to study, and the possibly confounding effects of overall violent crime and unemployment. We find that the effects are stronger among individuals for whom 6-12 years have elapsed since the school shooting. Many effects appear to dissipate among individuals for whom 13-18 years have elapsed since the shooting. Unfortunately, we cannot cleanly identify differences between age effects and elapsed time effects (this identification issue is discussed in e.g., Mason and Fienberg (1985); Heckman and Robb (1985)). Briefly, younger exposed individuals are also more likely to have been exposed more recently, so we cannot say whether our findings are due to age effects or elapsed time effects. In addition, measurement errors in assignment to treatment are also likely to be greater among the sample with longer durations from the shooting incidents.

The BRFSS provides no indication of in- or out-migration. If families with children affected by school shootings (or the children themselves as young adults), assuming negative causal effects of exposure, subsequently moved out of those counties, then the estimated 
effects would be biased toward zero. If these individuals get "locked" into those counties

subsequently, then the estimated effects would be biased away from zero. Our migration analyses following such events using the ACS shows that there is no evidence of differential migration between exposed and unexposed individuals. This finding lends credibility to the causal interpretation of our results using the BRFSS data.

The remainder of the paper is organized as follows. A brief survey of the existing literature can be found in section 2. In section 3, we describe the K12SSD, and BRFSS and ACS samples. In section 4, we describe the regression specifications used in this study. Results of the main and alternate specifications are described in section 5 , following which we conclude.

\section{Background}

Recently published papers demonstrate the short term effects of school shootings on exposed children. Beland and Kim (2016) found that ninth grade enrollment decreases in schools where a shooting occurred, while continuing students scored lower on math and English standardized tests. The standardized test scores are lower for continuing students for up to three years after a school shooting; the authors interpreted this finding as evidence that school shooting survivors are subjected to "medium-term trauma" (Beland and Kim, 2016). Levine and McKnight (2021) showed that school shootings, in addition to negatively affecting test scores, increase chronic absenteeism, and lead to a subsequent increases in suicides and accidental deaths, with boys being more affected by school shootings than girls. The authors also found that high fatality school shootings have significant negative effects on the surviving students, and that shootings with no or a low number of fatalities may also produce negative effects (Levine and McKnight, 2021).

Complementary work by Cabral et al. (2020) uses the universe of public school shootings in Texas and shows that exposed students have higher rates of absence and higher rates of chronic absenteeism relative to unexposed students for two years following a shooting. The exposed students are also more likely to repeat a grade within the same time period. The authors also found that exposure to a school shooting results in negative educational and employment outcomes. Exposed students are less likely to graduate from high school and less likely to enroll in and complete college; they also have decreased employment and 
earnings at 24-26 years of age. A paper by Rossin-Slater et al. (2020) examines the effect of fatal school shootings on youth antidepressant use for two subsequent years; the authors compared the number of antidepressant prescriptions written by providers practicing within five miles of an affected school with those written by providers in reference areas ten to fifteen miles away. They found, within this relatively short time frame, that the number of monthly antidepressant prescriptions written for individuals under the age of twenty is 21.3 percent higher within five miles of an affected school relative to the reference areas and that fatal school shootings have no effect on antidepressant use among adults.

The findings in the peer-reviewed literature on school shootings are consistent with reports in the press. Gaudiano (2019), writing for Politico, reported that federal aid applications made by school districts after shooting incidents describe significant deteriorations in academic performance, mental health and substance abuse among students in those districts. According to Fetters (2019) "death by suicide of someone connected to a school shooting is, unfortunately, a familiar story line."

We are aware of only one study (Bharadwaj et al., 2021) that examines the medium term effects of a mass shooting on exposed student outcomes. But it focuses on a narrower set of student outcomes, years of schooling and labor market participation, and its implications are limited in scope because the treatment group is based on one shooting at a Norwegian youth camp.

In a review of the clinical psychology literature, Orcutt et al. (2014) concluded that "the psychological consequences of directly experiencing or witnessing a mass shooting are often serious." Beyond the adverse individual-level effects, mass shootings also negatively affect the economic outcomes in the areas in which they occur (Soni and Tekin, 2020). Forthcoming work shows that mass shootings negatively affects employment, earnings, and housing prices at the county level (Brodeur and Yousaf, 2020). More broadly, adults who engage in unhealthy behaviors to a problematic degree are more likely to increase their engagement in these behaviors after being laid off (Deb et al., 2011). Soni and Tekin (2020) find that the negative effects of mass shootings spill over into the communities in which they occur and subsequently result in decreases in community wellbeing and emotional health, with greater reductions among parents with children under the age of 18 . However, the negative effects of 
an adverse event on health is more pronounced in children. In-utero exposure to mass shootings increases the occurrence of very low birth weight and very premature births (Dursun, 2019). Additionally, childhood adversity, such as mental or physical abuse, or witnessing the abuse of a caregiver, begins to affect health outcomes by early adolescence (Flaherty et al., 2013). Similarly, violence can also attribute to an "underlying risk profile" in children that remains dormant until adulthood and may result in the early onset of chronic health conditions (Taylor, 2010).

\section{Data}

\subsection{K-12 School Shooting Database (K12SSD)}

We use the K-12 School Shooting Database (K12SSD) to identify school shooting incidents (Riedman and O'Neill, 2020). This dataset, created by the Naval Postgraduate School's Center for Homeland Defense and Security, is intended to document "[each and every instance] a gun is brandished, is fired, or a bullet hits school property for any reason, regardless of the number of victims (including zero), time, day of the week, or reason [e.g. planned attack, accidental, domestic violence, gang-related, officer involved shooting]" (Riedman and O'Neill, 2020). The database includes shootings that range from incidents with no casualties (injuries or death) to mass shootings with large numbers of casualties. It documents over 1,400 shootings from 1970 to mid-2019 when we retrieved the database.

Our analysis is limited to school shootings in the contiguous United States (the 48 adjoining U.S. states plus the District of Columbia). We only consider incidents when the location is known to be "inside the school building" or "outside on school property". We do not consider shooting incidents when the type of school is "unknown", "other" or if the school is an elementary school. Elementary school shootings were rare during this period and have only recently become more prevalent capturing public attention. In most analyses, we eliminate shooting incidents in which there were no casualties (injured or killed victims). Following arguments by Levine and McKnight (2020), who demonstrate that different school shooting types affect different student populations, we estimate models using data on exposure limited to shootings that occurred only during school hours and also shootings that 
resulted in at least one death. We also expand the definition of exposure to include shooting incidents with no casualties.

We use data on school shootings from 1994 through 2005 for the analysis of health and human capital outcomes using the BRFSS. The K12SSD documents 237 incidents with one or more casualties (listed in Appendix Table A1). Of these, 19 counties have 2 incidents in the same year and 3 counties have 5 incidents in the same year. When more than one incident occurs in the same school in a year, we sum up the number of casualties and treat those incidents as one incident. Figure 1 shows the time series properties of school shootings. The number of incidents per year has a u-shape, rising at both ends of the analysis period. In some years, both incidents and casualties are high, but in other years casualties are high even when the number of incidents is low. Figure 2 shows the geographic dispersion of these school shootings. No region of the country is spared such incidents; 103 counties experienced 1 shooting incident, 24 counties experienced 2-3 incidents and 13 counties experienced 4 or more incidents.

We use data on school shootings from 1996 - 2018 for the analysis of migration using the ACS. The characteristics of shootings over time and space are qualitatively similar to those described above.

\subsection{The Behavioral Risk Factor Surveillance System (BRFSS)}

We use data from the 2003 to 2012 Behavioral Risk Factor Surveillance System (BRFSS) surveys to measure health, health-related behaviors, human capital and labor market outcomes of individuals 23-32 years old. The BRFSS is a nationwide telephone survey that collects data about US residents' self-perceived health status, health-related behaviors and chronic health conditions. It also includes measures of education, labor market status and income. Sponsored by the Centers for Disease Control and Prevention (CDC) and supported by a number of federal and state government agencies, the BRFSS currently collects data in all 50 states, the District of Columbia, and three US territories (Centers for Disease Control and Prevention, 2019). According to D. Flegel, a technical writer working on behalf of the CDC's public inquiry system, through 2005 the county code is set to missing if there were less than 50 respondents for a county, (personal communication, February 3, 2021). Addi- 
tionally, the county code is also set to missing if the population of the county is less than 10,000 adults (D. Flegel, personal communication, February 3, 2021). Our primary sample has data on individuals living in 1402 counties in the contiguous US. Also, note that BRFSS stopped reporting county identifiers after 2012.

We merge these data with the K12SSD using the county and year of school shooting incidents as identifiers. We restrict incidents to those that occur inside the school building or outside on school property. One county with a school shooting incident is not identifiable in the BRFSS data. In addition, 757 counties without shootings are not identifiable in the BRFSS data. Figure 2 shows their locations.

\subsection{American Community Survey (ACS)}

We use data from the 2004 to 2018 American Community Surveys (ACS) to measure migration. We retrieved the ACS data for those years from IPUMS USA (Ruggles et al., 2022). Public Use Microdata Area (PUMA) is the primary geographic identifier in the publicly available ACS (United States Census Bureau, 2022). When the respondent lives in a county with a sufficiently, large population, the county is identified too. Each year, the ACS asks respondents whether they moved homes in the previous year. Therefore, we replace the value of year used in our analysis with the year prior to the survey year. If the respondent did not move, then the location of that respondent in the previous year is the same as that in the survey year. If the respondent did move, the ACS records the respondent's geographic location prior to the move. We use that location associated with the year prior to the survey year in our analysis. Overall, 3,669 PUMAs are identified in our sample. About $60 \%$ of the ACS sample respondents live in one of the 472 identifiable counties. We merge these data with the K12SSD using the county and year and also by PUMA and year.

\subsection{Exposure}

A BRFSS respondent is defined as being exposed to a school shooting incident if that respondent lives in a county where a school shooting occurred and if they were between 11 and 17 years old in the year of the shooting. Individuals in our sample who lived in counties with a school shooting but who were not 11-17 years old during the shooting are defined as 
being unexposed. In addition, all other 23 to 32 old BRFSS respondents who live in counties without school shootings are defined as unexposed. We treat 18 year old individuals as unexposed because we cannot be sure of their schooling status. Appendix figure A1 shows the range of ages that can be exposed to shootings that occurred between 1994 and 2005 in each year of the BRFSS data.

In our primary analysis using the BRFSS, we define the treatment variable as taking the value of zero if the individual was not exposed to a school shooting inside the school building or outside on school property and as taking the value equal to the number of casualties (injured or killed) in the shooting incident inside the school building or outside on school property that the individual was exposed to. Table 1 shows that $8.2 \%$ of our sample was exposed to a school shooting. The median number of casualties among the exposed is 1 , while the 95 th percentile value is 5 . In specification checks, we define the treatment variable using incidents that occurred only during school days and separately using only those incidents that resulted in at least one death and measuring intensity using only counts of deaths. We also expand the definition of exposure to include shooting incidents with no casualties, and use a more narrow definition to include only mass shootings, ie., shootings that resulted in 3 or more casualties.

In the analysis of migration using the ACS, we conduct one analysis using individuals between 12-18 years old for whom exposure could have occurred 1-4 years ago. We conduct another analysis using individuals 19-23 years old for whom exposure could have occurred 2-8 years ago. We estimate regressions using counties as the geographic unit for a subsample of the ACS observations as well as regressions using PUMAs as the geographic unit. Table 4 shows the average intensity among those exposed - about 2 for each of the samples considered regardless of whether counties or PUMAs are used as the geographic unit.

\subsection{Covariates}

Our primary BRFSS sample consists of 197,426 women and 122,519 men between 23 and 32 years old (see table 1). We conduct our analysis separately for men and women. The median age in the primary sample is 28 .

Given our choice of ages of BRFSS respondents, the ages at which they were at risk of 
exposure, 6 to 18 years would have elapsed since the shooting up to the year of the survey. In the primary sample, among those exposed, the median time elapsed from shooting is 12 years. In order to differentiate between individuals who may have shorter time elapsed from the date of the shooting as compared to those with longer elapsed times, we also estimate the models after restricting our sample to those exposed 6-12 years ago, and those exposed between 13-18 years ago. In the shorter elapsed time sample, the median time elapsed since shooting in this sample is 10 years; the median age is 28 years. In the longer elapsed time sample, the median cohort time elapsed is 15 years and the median age is 29 years.

Among respondents not exposed to school shootings, $12 \%$ of women and $7 \%$ of men identify as Black (see table 2). In contrast, among those exposed to a school shooting, about $24 \%$ of women and $15 \%$ of men identify as Black. Table 2 also shows that women and men in other minority groups are also overrepresented in the exposed group relative to the unexposed.

Table 4 presents summary statistics for the ACS samples of men and women. As with the BRFSS sample, the rates of minority women and men exposed to school shootings is higher than those rates among the unexposed.

\subsection{Outcomes}

We examine the effects of exposure to school shootings on measures of risky behavior, health and human capital outcomes. Table 3 lists all the measures and presents summary statistics.

We examine cigarette smoking, alcohol consumption, and physical exercise as measures of risky behaviors. We examine cigarette smoking using a binary indicator ever smoked for whether a person smoked at least 100 cigarettes in their lifetime. We then examine current

smoking status among those who had ever smoked using a multinomial variable that takes 3 values: quit, smokes daily and smokes occasionally. We use counts of the number of drinking days, the maximum number of drinks on one occasion and the number of days $\geq 5$ drinks to measure alcohol consumption. We use a binary indicator for no physical exercise.

We examine self-reported health and mental health status as our health measures. Self reported health status is measured as a multinomial variable defined by excellent or very good health, good health and fair or poor health. Mental health is measured as a count of the 
number of not good mental health days.

Education status is measured as a multinomial variable with levels: high school graduate, not a high school graduate, attended technical school or college and graduated technical school or college. Income is measured in 8 intervals with lower limits set at $\$ 0, \$ 10,000$, $\$ 15,000, \$ 20,000, \$ 25,000, \$ 35,000, \$ 50,000$ and $\$ 75,000$. For employment status, we use a binary indicator for working in contrast to not working for the sample of men. However, in preliminary analysis on the sample of women, we observed differences between women who were not employed because they were homemakers and women who reported other reasons for not working. Therefore, we chose to model employment status for the sample of women using a multinomial variable with three categories: employed, homemaker and not working.

We measure migration in two ways using the ACS. First, we limit the samples to those who lived in a county identified by its FIPS code in the year prior to the survey. We define a person as having moved if that person lived in a different county in the year of the survey as compared to the county in the year prior to the survey. We allow for moves to counties that are not specifically identified, e.g., most rural counties. The sample restriction only applies to the identity of the county prior to the move. Second, we define a person as having moved if that person moved between PUMAs from the year prior to the survey year. We use the identity of the PUMA in the year prior to the survey for merging with the school shootings database, but not to determine the move; the ACS has a variable that identifies all moves.

The rates of across county moves in the samples restricted to those respondents for whom the origin county is known and the rates of across PUMA moves are very similar in areas that are unexposed to school shootings (Table 4). For 12-18 year olds the rate is about 8\%; for 19-23 year olds the rate is about 13\%. Among areas that are exposed, the rates of across county moves are similar to those in unexposed areas. But the rates of across PUMA moves are substantially lower than the other rates. The migration regressions confirm our initial conjecture that these differences are due to the types of PUMAs where school shootings occur rather than being the effect of the incidents themselves. Our concerns about migration are further mitigated by the findings in Cabral et al. (2020), where using more granular data, the authors find no evidence of students switching schools, or leaving the public school system after a school shooting. 


\section{Econometric specification}

\subsection{Model}

Denote individuals by $i=1,2, \ldots, N$, counties in the US by $j=1,2, \ldots, J$ and years of the survey in the study by $t=1,2, \ldots, T$. Denote the number of casualties due to exposure to a school shooting for individual $i$ in county $j$ at time $t$ by $c_{i j t}$. Let $\boldsymbol{x}_{i j t}$ denote age and race indicators. Let $d_{i c t}$ denote the duration from the school shooting to the year of the survey for an exposed individual. Duration is set to zero for unexposed individual.

For each outcome, we estimate a regression model with the following functional form:

$$
\mathrm{E}\left(y_{i j t}\right)=f\left(c_{i j t} \beta_{c}+\boldsymbol{x}_{i j t} \boldsymbol{\beta}_{\boldsymbol{x}}+\beta_{d} d_{i j t}+\nu_{j}+\omega_{t}\right)
$$

where $\nu_{j}$ denotes county fixed effects and $\omega_{t}$ denotes year fixed effects. Note that we enter duration as a linear, continuous variable to avoid the identification issues introduced if indicators for age and year and duration are all entered together (Mason and Fienberg, 1985; Heckman and Robb, 1985).

In the cases where the outcome, $y_{i j t}$ is binary, we estimate a logistic regression with equation 1 guiding covariates. In the cases where the outcome is multinomial, we estimate a multinomial logit regression. When the outcome is measured as a count variable, we estimate Poisson regressions with covariates specified according to equation 1. Finally, for income, which is reported as an interval measure in the BRFSS, we estimate an interval regression for the intervals of the logarithm of income. Income is substantially skewed while the distribution of the log of income is considerably symmetric.

Note that the regressions include location (county for all BRFSS regressions and county or PUMA for ACS regressions) and year fixed effects, so the coefficient on the exposure variable, $c_{i j t}$, is identified using two sources of variation. One source of variation is the comparison of respondents living in a county who were exposed to a shooting (determined by the difference between their current age and the date of the shooting) and respondents in the same county who were not exposed to a shooting. The second source of variation is the comparison between the outcomes of respondents who live in counties without shootings with exposure potential (based on their age) compared to individuals without exposure potential serves to partial out effects of unobserved confounders. 
The current literature suggests that school shootings affect boys and girls differently (Levine and McKnight, 2021). Therefore, we estimate our model for exposed male and female students separately. For each regression, we report exponentiated coefficients on exposure, $\exp \left(\beta_{c}\right)$. These have the virtue of being interpretable as percentage changes in the outcome across all measure types. Standard errors of coefficients are estimated using the sandwich formula that adjusts for clustering of regression errors at the state level. We report p-values of the null hypothesis that the exponentiated coefficient equals 1 along with $95 \%$ confidence intervals in the figures and tables described below.

\section{$4.2 \quad$ Specification checks}

The first set of specification checks of the BRFSS analysis considers alternatives to our measure of exposure. First, we eliminate counties that had more than 4 shootings out of concern for the possibility that counties with multiple shootings may be different in ways not accountable by use of fixed effects. Second, we drop counties with more than 20 schools. Such counties, which comprise about $12 \%$ of all counties have many more schools than the typical county and much larger populations. As described above, in our primary analyses we define exposure using incidents that occurred inside the school building or outside on school property and that resulted in at least one casualty (injured or killed). We consider a number of specification checks of this decision. First, we define exposure using only those incidents that resulted in deaths with the measure of intensity being the number of deaths. Second, we limit exposure to incidents that occurred only during a school day (excluding events). Third, we include additional shooting incidents in which there were no casualties. Finally, we limit incidents to those defined as mass shootings only, i.e., those with three or more casualties.

In our second set of specification checks, we first conduct two analyses that change the period of shooting incidents used in the analysis. Relative to the main sample period of 1994 - 2005, we expand the shooting incidents period to be from 1993 - 2006 and we contract the period to be from 1995 - 2004. Second, we address a concern arising from the fact that individuals who were exposed to shootings are, on average, younger and more likely to be of minority race and/or Hispanic ethnicity. We balance the exposed and unexposed samples 
on these characteristics, by calculating sampling weights for the unexposed sample using an entropy balancing technique developed by Hainmueller (2012). Third, we estimate regression specifications that control for annual county unemployment rates. Data on annual county unemployment rates were obtained from the Bureau of Labor Statistics (2021). Fourth, we estimate regression specifications that control for annual county-level homicide rates. We use the annual county-level homicide rates as a proxy for overall crime. The overall crime that the BRFSS respondents are exposed to may influence their likelihood to engage in risky health behaviors. Homicide rates were obtained from Kaplan (2021). Finally, we estimate regressions after limiting the samples to exclude high migration counties. Data on net migration was obtained from the University of Wisconsin-Madison's Center for Demography and Ecology (Voss et al., 2004). We calculated net migration rates of counties over the 1990-2000 decade for 20-35 year old individuals (in the year 2000). By eliminating counties that were in the top 5th percentile of net in-migration and those in the top 5 th percentile of net out-migration (a total of 134 counties), we restrict the sample to individuals who were more likely to have lived in the same county throughout.

Two of the specification checks described above involve including additional control variables on the right-hand side of the regression, implicitly arguing that our results are robust if their inclusion do not significantly affect coefficients of interest. But Pei et al. (2019) show that such insignificance may be due to the fact that these variables are poor measures of the underlying confounders. They recommend using these variables as outcomes in the regression specifications as more powerful tests of the identifying assumption.

We also estimate two sets of regressions in which assignments to treatment are placebos. In the first set of placebo regressions, a BRFSS respondent is defined as being exposed to a school shooting incident if that respondent lived in a county where a school shooting occurred and if they were between 4 and 10 years old in the year of the shooting. These individuals are 7 years younger than the actual treated individuals. For this specification, the sample includes 20-29 year old individuals, who are 3 years younger than those chosen for the primary sample. Ideally, we would have preferred to lower the ages of sampled individuals by 7 years to be consistent with the placebo-treated individuals. Unfortunately, using 18 and 19 year olds in the sample would likely contaminate the placebo assignment with actual exposure. 
In the second set of placebo regressions, respondents who lived in counties where a shooting occurred when they were between 20 and 26 years old were defined as being exposed, 9 years older than the actual treated individuals. In keeping with the spirit of the cohorts for the first set of placebo regressions, for this specification, the sample includes 28-37 year old individuals who are 5 years older than those in the primary sample. We should note that these are not strictly placebo regressions because we cannot rule out possible exposure among these older and younger individuals. For example, some of these individuals may have been siblings of exposed high schoolers. Others may attend schools that were geographically contiguous or close to the high schools in which shootings occurred.

We also consider a set of specification checks for the migration regressions using the ACS. In the primary specification, a respondent is exposed to a shooting incident only if it occurred at least one year prior to the potential move year, and up to 4 years prior. But that means, if a respondent moved "immediately" in response to a school shooting, that exposure would not be recorded as such. So, in a specification check, we define exposure using incidents from the year of a potential move as contributing to exposure. This check introduces the possibility of a different measurement error - that moves prior to the shooting incident in the year of the incident would be recorded as exposure when it should not.

\section{$5 \quad$ Results}

\section{$5.1 \quad$ BRFSS}

For the primary sample of women using data from the BRFSS, Figure 3 displays effects reported as exponentiated coefficients with associated $95 \%$ confidence intervals associated with the effect of being exposed to a shooting incident on each of the outcomes described above. We find that exposure to school shooting affects drinking behavior. There is weak evidence that the number of drinking days increases (p-value 0.158). However, there is statistically significant evidence that an additional shooting casualty increases the maximum number of drinks an affected woman drinks on one occasion by 0.5 percent and increases the risk of drinking 5 or more drinks by 1.8 percent.

We also find that school shootings affect educational attainment, income and labor force 
participation among women. Relative to being a high school graduate, exposure to an additional shooting casualty increases the likelihood of not being a high school graduate by 1.1 percent and increases the likelihood of attending college or technical school by 0.7 percent. The likelihood of graduating college is not significantly affected by exposure to school shootings. Exposure to a school shooting casualty reduces women's income by 0.5 percent relative to unexposed women. As described above, we examine female labor force participation using a multinomial variable with three categories. We find that, relative to the likelihood of being employed, exposure to a school shooting casualty increases the likelihood of being unemployed by 2.2 percent and the likelihood of being a homemaker by 1.2 percent.

In our sample of women, we find that exposure to school shootings has no effects on smoking, both as measured by the likelihood of ever having smoked cigarettes and on the likelihood of being a current smoker or a past smoker (but having quit) among those who had ever smoked. Exposure to school shootings also has no statistically significant effect on the ways in which women report their own general health. Exposed women also do not report significantly different numbers of not good mental health days compared to the unexposed.

Figure 4 displays the effects of exposure to school shootings for the primary sample of men using data from the BRFSS. In contrast to the results for women, the risk of smoking among men is modified by exposure. Exposure to a school shooting casualty increases the risk of smoking daily among men who have ever smoked by 1.7 percent relative to men who were not exposed. Analogous to the results for women, we find substantial, statistically significant effects of exposure to school shootings on the alcohol consumption behavior of men. Exposure to a shooting increases, per casualty, the number of drinking days by 0.5 percent, increases the maximum number of drinks an affected man drinks on one occasion by 0.3 percent and increases the number of drinking days where five or more drinks are consumed by 1.2 percent. Men are also much less likely to engage in physical exercise postexposure; the likelihood of not engaging in physical exercise increases by 1.5 percent, per school shooting casualty.

Among men, exposure to school shootings also has human capital effects, although the effects are less noticeable compared to the effects observed in our sample of women. Exposure to a school shooting increases the likelihood of attending college or technical school by 1.4 
percent with no changes in the likelihoods of not graduating from high school or graduating from college relative to graduating from high school. Income decreases by 0.5 percent, per casualty, among exposed men as compared to those not exposed. The effect on employment status is small and statistically insignificant.

\section{$5.2 \quad$ ACS}

The top panel of Table 5 show the effects of exposure to school shooting incidents among 12-18 year olds exposed 1-4 years prior to the potential move year. Recall that the potential move year is one year prior to the ACS survey year. There is no indication of moves out of the county or PUMA in response to a school shooting. There is weak evidence, for the sample of men, that 12-18 year olds may be less likely to move following a school shooting. The bottom panel of Table 5 show the effects of exposure to school shooting incidents among 19-23 year olds exposed 1-8 years prior to the potential move year. This age group has the ability to move by themselves, i.e., without a parent; they may move away to college, or for jobs elsewhere. There is no evidence whatsoever of differential probabilities of migration by exposure to school shootings.

This analysis provides confidence in the causal interpretations of the effects of school shootings on health and human capital outcomes. Recall that the BRFSS provides no indication of whether the person moved into the current county of residence recently or whether they have lived there all their lives. In other words, we cannot identify in- or out-migration in the data. The results of these regressions show conclusively that exposure to school shootings does not lead to significant migration.

\subsection{BRFSS: Stratified by duration since exposure}

We estimate separate models after splitting the sample of exposed individuals into two groups. In one group, the duration between exposure to the shooting and the BRFSS survey is 6-12 years. In the other, the duration between exposure and the survey is 13-18 years. To be precise, beginning with the main samples of women and men, we drop exposed individuals if they do not meet the definition of the duration constraint. The sample of unexposed individuals remains the same. 
In the analysis of women restricted to those whose exposures occurred 6-12 prior to the survey, we find that the results are consistent with those obtained using the corresponding full sample. The number of drinking days increases by 0.6 percent, per casualty, and the maximum number of drinks consumed is 0.4 percent higher. For each additional casualty they are exposed to, women show an increase of 1.6 percent in the number of drinking days where five or more drinks are consumed. Women exposed to school shootings 6-12 years prior to the survey are 1 percent less likely to graduate from high school and more likely, by 0.6 percent, to attend college or technical school, but not graduate. Exposure to a school shooting leads to significant declines in income - by 0.6 percent for women. Finally, the evidence shows that, among women, exposure 6-12 years prior to the survey increases the likelihood of not working by 2.7 percent and of being a homemaker by 1.7 percent. These results are available in Appendix figure A2.

We find that the effects diminish in magnitudes and statistical significance for many outcomes from the sample with shorter duration from exposure to survey to the sample with longer periods. Most of the effects of school shootings are not statistically significant although generally the signs are consistent with the results for the full sample of women.

In the sample of men, the results of the analysis restricted to those whose exposures occurred 6-12 prior to the survey are consistent with those obtained using the corresponding full sample. Appendix figure A3 displays these findings. There is clear evidence of more frequent and greater alcohol consumption. There is also evidence of more risky behavior. As with the sample of women, we find that the effects diminish in magnitudes and statistical significance for many outcomes from the sample with shorter duration from exposure to survey to the sample with longer periods. Nevertheless, exposure to school shootings 13-18 years ago is significantly associated with higher risk of smoking daily, with greater number of drinking days, with higher risk of no physical exercise and the number of days without enough rest. Exposure also increases the risk not graduating from high school.

\subsection{BRFSS: Specification checks}

We conduct a number of checks to our basic specifications focus on possible errors in the measurement of exposure. The results of these analyses, for the samples of women and men, 
are shown in Figures 5 and 6 respectively. First, note that, because we can only assign a shooting incident to a county, and because most counties have more than one high school, we cannot be sure that an individual designated as being exposed was actually exposed. As a counterargument to this possibility, note that Gaudiano (2019) reports that effects of school shootings do spread through entire school districts which are often geographically aligned with counties. Nevertheless in one specification check, we drop counties with more than 20 schools. Such counties, which comprise about $12 \%$ of all counties have many more schools than the typical county and much larger populations. The results are consistent with those obtained in the primary analysis. Second, we eliminate counties that had more than 4 shootings in one analysis out of concern for the possibility that counties with multiple shootings may be different in ways not accountable by use of the county fixed effects.

Not all shootings are the same. Accuracy of measurement might vary by the nature of the incident. Students and others might be affected in different ways (Levine and McKnight, 2020). Therefore, we also estimate models using data on exposure limited to shootings that resulted in at least one death. In another analysis, we only consider incidents with casualties that occurred during school days. This definition is more stringent than one we considered in our primary analyses that restricted exposure to incidents with casualties that occurred during school days or school extra-curricular events. In yet another analysis, we consider an expansion of the types of incidents included in the measure of exposure. We include the $12.8 \%$ of shooting incidents recorded in the K12SSD that meet our school type and location criteria with no casualties in our definition of exposure. We code exposure equal to one if the shooting incident had no casualties, and exposure equal to the number of casualties plus one for incidents with casualties. In a final analysis, we restrict shooting incidents to include only those defined as mass shootings, i.e., incidents that involved three or more casualties. In cases except the specification that measures intensity using counts of deaths only, the results are qualitatively similar to the primary analyses.

When the intensity of shooting incidents is defined using counts of only deaths, Figures 5 and 6 show that the estimated effects are typically larger than when intensity is defined as the count of casualties. This feature may have a simple explanation. For every death in a school shooting incident, there are likely non-fatal casualties as well. So, if the effect of 
a shooting is independent of whether the casualty is fatal or not, the marginal effect of an additional death would be larger than the marginal effect of a casualty, all else equal.

We conduct two analyses that change the period of shooting incidents used in the analysis. Relative to the main sample period of 1994 - 2005, we expand the period of shooting incidents to be from 1993 - 2006 and we contract the period to be from 1995 - 2004. In both cases, the results, shown in Appendix figures A4 and A5 are consistent with those of the primary analysis. Second, we address a concern arising from the fact that individuals who were exposed to shootings are, on average, younger and more likely to be of minority race and/or Hispanic ethnicity (Table 2). Although controlling for these characteristics in our regressions and including county fixed effects should mitigate any confounding due to these differences, we try to mitigate any such effects further by balancing the exposed and unexposed samples on these characteristics. We do so by calculating sampling weights for the unexposed sample using an entropy balancing technique developed by Hainmueller (2012) that leads to the treated and untreated samples to have very similar weighted sample characteristics. Entropy balance combined with regression is doubly robust (Zhao and Percival, 2017). The results of these analyses for the samples of women and men, shown in Figures A4 and A5 respectively, are consistent with the primary results.

Might changes in local socioeconomic characteristics, not taken into account in the county fixed effects, produce substantial omitted variable biases? To examine such possibilities, we estimate regression specifications that control for annual county unemployment rates. We also estimate regression specifications that control for annual county-level homicide rates. In both cases, we find that results do not change in any substantive ways. Finally, as noted above, we cannot identify in- or out-migration in the BRFSS data. Therefore, we estimate specifications based on samples that eliminated counties which were in the top 5th percentile of net in-migration and those in the top 5th percentile of net out-migration (a total of 134 counties). The estimates of the effects of school shootings remain virtually unchanged.

To take the criticism of such additional-control checks of Pei et al. (2019) into account, we estimate regressions with county level unemployment and homicide rates as outcomes, holding the right hand sides of the specifications the same. Results shown in Appendix A3 show that the effects of shooting exposure are small and statistically significant, which we 
interpret as another confirmation of the validity of our results.

We also conduct two sets of placebo-like regressions, results of which are available in Appendix figures A6 and A7. In the first set of placebo regressions, individuals who were between 4 and 10 years old in the year (and county) of a shooting are defined as exposed. The effects are overwhelmingly insignificant among women and men. In the case of men, all three statistically significant effects (ever smoked, number of drinking days and no physical exercise), suggest that exposed men have better health and health behaviors. If these are not spurious, these findings would suggest that sources of bias would bias coefficients in the primary regressions, where we find evidence of worse health, toward zero.

In the second set of placebo regressions, individuals who lived in counties where a shooting occurred when they were between 20 and 26 years old were defined as being exposed. The effects are overwhelmingly insignificant for both samples of women and men. Exposed women appear significantly less likely to be not working or homemakers, which are opposite in sign to the results we find in the primary sample. Again, if these are not spurious, these findings would suggest that sources of bias would bias coefficients in the primary regressions toward zero.

We also consider a set of specification checks for the migration regressions using the ACS. In the primary specification, a respondent is exposed to a shooting incident only if it occurred at least one year prior to the potential move year, and up to 4 years prior. But that means, if a respondent moved "immediately" in response to a school shooting, that exposure would not be recorded as such. So, in a specification check, we define exposure using incidents from the year of a potential move as contributing to exposure. This check introduces the possibility of a different measurement error - that moves prior to the shooting incident in the year of the incident would be recorded as exposure when it should not.

\section{Conclusion}

In this paper, we examine the effects of school shootings on health, health-related behaviors and human capital outcomes of exposed students as adults in their twenties and early thirties. We use data from K12SSD, a comprehensive database of school shootings, the BRFSS and the ACS, to estimate the effects of exposure to school shootings while in high school. 
Our study has three main limitations. First, because we are only able to match BRFSS respondents to the shooting incidents by county, we cannot identify whether a high school age individual in a county actually attended the school in which a shooting occurred. This measurement error likely means that our estimates are lower bounds of the true effects of school shootings. We also recognize that we do not fully address the effect of being exposed to a school shooting by race. We are unable to do so because the samples of individuals who identify as belonging to a minority racial group are too small, creating power issues. Finally, we are not able to test the mechanisms through which exposure to school shootings affect our outcomes of interest. As we alluded to earlier in our paper, the "toxic stress" from these "intense adverse experiences" may be a mechanism worth exploring. We leave this to future research.

However, despite our limitations, among women and men, we find substantial evidence of declines in health and well-being, worse health-related behaviors and worse education and labor market outcomes. The results are robust in a variety of specification checks. We use data from the ACS to show that exposure to school shootings does not lead to significant migration. We cannot identify in- or out-migration in the BRFSS data. Therefore the analysis of migration using the ACS provides confidence in the causal interpretations of the effects of school shootings on health and human capital outcomes. 


\section{References}

Ang, D. (2021). The effects of police violence on inner-city students. The Quarterly Journal of Economics, 136(1):115-168.

Beland, L.-P. and Kim, D. (2016). The effect of high school shootings on schools and student performance. Educational Evaluation and Policy Analysis, 38(1):113-126.

Bharadwaj, P., Bhuller, M., Løken, K. V., and Wentzel, M. (2021). Surviving a mass shooting. Journal of Public Economics, 201:104469.

Bor, J., Venkataramani, A. S., Williams, D. R., and Tsai, A. C. (2018). Police killings and their spillover effects on the mental health of black americans: a population-based, quasi-experimental study. The Lancet, 392(10144):302-310.

Brodeur, A. and Yousaf, H. (2020). On the economic consequences of mass shootings.

Bureau of Labor Statistics (2021). Labor for data by county. https://www.bls.gov/lau/ \#cntyaa.

Cabral, M., Kim, B., Rossin-Slater, M., Schnell, M., and Schwandt, H. (2020). Trauma at school: The impacts of shootings on students' human capital and economic outcomes. Technical report, National Bureau of Economic Research.

Centers for Disease Control and Prevention (2019). Behavioral Risk Factor Surveillance System. https://www.cdc.gov/brfss/index.html. (Accessed on May 26, 2019).

Cook, P. J. (2020). Thinking about gun violence. Criminology \& Public Policy, 19(4):13711393.

Cox, J. W., Rich, S., Chiu, A., Muyskens, J., and Ulmanu, M. (2019). Analysis | More than 240,000 students have experienced gun violence at school since Columbine. Washington Post.

Deb, P., Gallo, W. T., Ayyagari, P., Fletcher, J. M., and Sindelar, J. L. (2011). The effect of job loss on overweight and drinking. Journal of health economics, 30(2):317-327.

Dursun, B. (2019). The intergenerational effects of mass shootings. Available at SSRN 3474544 .

Fetters, A. (2019). Lasting grief after a mass shooting. The Atlantic. https: //www.theatlantic.com/education/archive/2019/03/grief-school-shootingssuicide/585865/.

Flaherty, E. G., Thompson, R., Dubowitz, H., Harvey, E. M., English, D. J., Proctor, L. J., and Runyan, D. K. (2013). Adverse childhood experiences and child health in early adolescence. JAMA Pediatrics, 167(7):622-629. 
Gaudiano, N. (2019). Parkland and santa fe schools disclose devastating after-effects of shootings. Politico. https://www.politico.com/news/2019/10/10/parkland-santafe-school-shootings-effects-students-043687.

Grossman, D., Cawley, J., and de Walque, D. (2018). Effect of stress on later-life health: Evidence from the vietnam war draft. Southern Economic Journal, 85(1):142-165.

Hainmueller, J. (2012). Entropy Balancing for Causal Effects: A Multivariate Reweighting Method to Produce Balanced Samples in Observational Studies. Political Analysis, 20(1):25-46.

Heckman, J. and Robb, R. (1985). Using Longitudinal Data to Estimate Age, Period and Cohort Effects in Earnings Equations. pages 137-150. Springer, New York, NY.

Kaplan, J. (2021). Jacob kaplan's concatenated files: Uniform crime reporting program data: Offenses known and clearances by arrest (return a), 1960-2020. https: //www .openicpsr .org/openicpsr/project/100707/version/V17/view ; jsessionid=6A0A00E0C2E3166E1D02C612F90F6980?path=/openicpsr/100707/fcr: versions/V17/ucr_offenses_known_monthly_1960_2020_dta.zip\&type=file.

Levine, P. B. and McKnight, R. (2020). Not all school shootings are the same and the differences matter. Technical report, National Bureau of Economic Research.

Levine, P. B. and McKnight, R. (2021). Exposure to a school shooting and subsequent well-being. Technical report, National Bureau of Economic Research.

Mason, W. M. and Fienberg, S. E. (1985). Introduction: Beyond the Identification Problem. pages 1-8. Springer, New York, NY.

Middlebrooks, J. S. and Audage, N. C. (2008). The effects of childhood stress on health across the lifespan. National Center for Injury Prevention and Control of the Centers for Disease Control.

Orcutt, H. K., Miron, L. R., and Seligowski, A. V. (2014). Impact of mass shootings on individual adjustment. PTSD Research Quarterly, 25(3):1-9.

Pei, Z., Pischke, J.-S., and Schwandt, H. (2019). Poorly Measured Confounders are More Useful on the Left than on the Right. Journal of Business \& Economic Statistics, 37(2):205216.

Riedman, D. and O'Neill, D. (2019). K-12 school shooting database. naval postgraduate school, center for homeland defense and security. (Accessed on May 20, 2019).

Riedman, D. and O'Neill, D. (2020). K-12 school shooting database: Research methodology. Naval Postgraduate School, Center for Homeland Defense and Security, Homeland Security Advanced Thinking Program.

Rossin-Slater, M., Schnell, M., Schwandt, H., Trejo, S., and Uniat, L. (2020). Local exposure to school shootings and youth antidepressant use. Proceedings of the National Academy of Sciences, 117(38):23484-23489. 
Ruggles, S., Flood, S., Goeken, R., Schouweiler, M., and Sobek, M. (2022). IPUMS USA: Version 12.0 [dataset]. Minneapolis, MN.

Soni, A. and Tekin, E. (2020). How do mass shootings affect community wellbeing? Technical report, National Bureau of Economic Research.

Taylor, S. E. (2010). Mechanisms linking early life stress to adult health outcomes. Proceedings of the National Academy of Sciences, 107(19):8507-8512.

United States Census Bureau (2022). Public Use Microdata Areas (PUMAs). https://www. census.gov/programs-surveys/geography/guidance/geo-areas/pumas.html. (Accessed on June 6, 2022).

Voss, P. R., McNiven, S., Hammer, R. B., Johnson, K. M., and Fuguitt, G. V. (2004). County-specific net migration by five-year age groups, hispanic origin, race and sex 19902000. Madison: Center for Demography and Ecology, University of Wisconsin-Madison (working paper 2004-24).

Zhao, Q. and Percival, D. (2017). Entropy Balancing is Doubly Robust. Journal of Causal Inference, 5(1). 
Table 1: Characteristics of casualties and duration in primary sample and strata of duration since exposure

\begin{tabular}{lccccccccc}
\hline \multirow{2}{*}{ Sample definition } & \multicolumn{2}{c}{ Sample size } & $P_{50}$ & \multicolumn{2}{c}{ Percent } & \multicolumn{3}{c}{ Casualties } & \multicolumn{3}{c}{ Duration from exposure } \\
& Female & Male & age & exposed & $P_{50}$ & $P_{95}$ & $P_{50}$ & Min & Max \\
\hline Full sample & 197426 & 122519 & 28 & 8.2 & 1 & 5 & 12 & 6 & 18 \\
6-12 years duration & 189119 & 117150 & 28 & 4.5 & 1 & 4 & 10 & 6 & 12 \\
13-18 years duration & 188184 & 116623 & 29 & 4.1 & 2 & 5 & 15 & 13 & 18 \\
Incidents with deaths only & 197426 & 122519 & 28 & 4.4 & 1 & 3 & 12 & 6 & 17 \\
Incidents during school day or events & 197426 & 122519 & 28 & 5.5 & 2 & 3 & 12 & 6 & 17 \\
\hline
\end{tabular}

Note: The primary sample consists of individuals ages 23-32 living in 1402 counties from 2003-2012 BRFSS. $P_{50}$ is the median among those exposed. $P_{95}$ is the $95^{\text {th }}$ percentile value in the sample among those exposed. Min and Max denote the minimum and maximum sample values among those exposed. 
Table 2: Means of covariates in primary samples of women and men

Sample of women Sample of men
Not exposed exposed Not exposed exposed

\begin{tabular}{lcccc}
\hline Age in years & 28.19 & 26.85 & 28.10 & 26.80 \\
Black race & 0.12 & 0.24 & 0.07 & 0.15 \\
Non-Black Hispanic ethnicity & 0.13 & 0.20 & 0.12 & 0.19 \\
Other race & 0.06 & 0.09 & 0.07 & 0.11 \\
\hline
\end{tabular}

Note: The primary sample consists of individuals ages 23-32 living in 1402 counties from 2003-2012 BRFSS. 
Table 3: Means of outcomes in primary samples of women and men

\begin{tabular}{|c|c|c|c|c|c|c|}
\hline & \multicolumn{3}{|c|}{ Sample of women } & \multicolumn{3}{|c|}{ Sample of men } \\
\hline & \multirow[t]{2}{*}{$\mathrm{N}$} & \multicolumn{2}{|c|}{ mean } & \multirow[t]{2}{*}{$\mathrm{N}$} & \multicolumn{2}{|c|}{ mean } \\
\hline & & Not exposed & exposed & & Not exposed & exposed \\
\hline Ever smoked & 196,589 & 0.376 & 0.302 & 121,840 & 0.454 & 0.409 \\
\hline Among ever smoked: quit & 69,464 & 0.435 & 0.390 & 51,030 & 0.419 & 0.372 \\
\hline smokes daily & & 0.175 & 0.213 & & 0.207 & 0.259 \\
\hline smokes occasionally & & 0.390 & 0.397 & & 0.374 & 0.369 \\
\hline No. of drinking days & 137,926 & 3.821 & 4.738 & 99,132 & 6.850 & 7.382 \\
\hline Max drinks on one occasion & 78,877 & 3.284 & 3.407 & 63,098 & 5.978 & 5.836 \\
\hline No. of days $>=5$ drinks & 101,618 & 0.853 & 1.077 & 82,769 & 2.174 & 2.177 \\
\hline No physical exercise & 196,195 & 0.209 & 0.214 & 121,567 & 0.168 & 0.152 \\
\hline Health: excellent or v. good & 192,815 & 0.621 & 0.614 & 115,047 & 0.636 & 0.643 \\
\hline good & & 0.287 & 0.291 & & 0.280 & 0.274 \\
\hline fair or poor & & 0.092 & 0.095 & & 0.084 & 0.082 \\
\hline No. of not good mental health days & 195,394 & 4.500 & 4.412 & 121,332 & 3.268 & 3.402 \\
\hline Education level: HS graduate & 188,437 & 0.088 & 0.099 & 112,535 & 0.093 & 0.083 \\
\hline not HS graduate & & 0.239 & 0.206 & & 0.282 & 0.233 \\
\hline attended college/tech & & 0.296 & 0.269 & & 0.266 & 0.262 \\
\hline graduated college/tech & & 0.377 & 0.426 & & 0.359 & 0.421 \\
\hline Income $\$ 0-\$ 9,999$ & 180,372 & 0.064 & 0.087 & 112,680 & 0.037 & 0.054 \\
\hline$\$ 10,000-\$ 14,999$ & & 0.056 & 0.067 & & 0.039 & 0.051 \\
\hline$\$ 15,000-\$ 19,999$ & & 0.087 & 0.097 & & 0.073 & 0.077 \\
\hline$\$ 20,000-\$ 24,999$ & & 0.109 & 0.106 & & 0.102 & 0.105 \\
\hline$\$ 25,000-\$ 34,999$ & & 0.142 & 0.136 & & 0.143 & 0.128 \\
\hline$\$ 35,000-\$ 49,999$ & & 0.174 & 0.154 & & 0.189 & 0.158 \\
\hline$\$ 50,000-\$ 74,999$ & & 0.177 & 0.151 & & 0.195 & 0.174 \\
\hline$\$ 75,000-$ & & 0.190 & 0.202 & & 0.222 & 0.254 \\
\hline Employment: working & 195,211 & 0.651 & 0.625 & 122,188 & 0.840 & 0.779 \\
\hline not working & & 0.167 & 0.226 & & 0.160 & 0.221 \\
\hline homemaker & & 0.183 & 0.148 & & & \\
\hline
\end{tabular}

Note: The primary sample consists of individuals ages 23-32 living in 1402 counties from 2003-2012 BRFSS. 
Table 4: Means of covariates and outcome in the analysis using ACS data

\begin{tabular}{lcccc}
\hline & \multicolumn{3}{c}{ Sample of women } & \multicolumn{2}{c}{ Sample of men } \\
& Unexposed & Exposed & Unexposed & Exposed \\
\hline 12-18 year olds in identified & counties & potentially exposed 1-4 years ago \\
Age in years & 15.026 & 15.190 & 15.018 & 15.188 \\
Black race & 0.126 & 0.185 & 0.127 & 0.186 \\
Non-Black Hispanic ethnicity & 0.213 & 0.322 & 0.214 & 0.326 \\
Other race & 0.180 & 0.231 & 0.178 & 0.228 \\
Number of casualties & 0.000 & 2.049 & 0.000 & 2.048 \\
Across county moves & 0.085 & 0.071 & 0.080 & 0.069 \\
N & 953263 & 277824 & 1007489 & 292604 \\
\multicolumn{4}{c}{} & \\
$\quad$ 12-18 year olds in PUMAs potentially exposed & $1-4$ years ago \\
Age in years & 15.046 & 15.104 & 15.042 & 15.110 \\
Black race & 0.120 & 0.208 & 0.121 & 0.205 \\
Non-Black Hispanic ethnicity & 0.182 & 0.201 & 0.183 & 0.201 \\
Other race & 0.153 & 0.146 & 0.151 & 0.142 \\
Number of casualties & 0.000 & 1.576 & 0.000 & 1.566 \\
Across PUMA moves & 0.081 & 0.030 & 0.076 & 0.028 \\
N & 2029193 & 50778 & 2149812 & 54014
\end{tabular}

19-23 year olds in identified counties potentially exposed 1-8 years ago

$\begin{array}{lcccc}\text { Age in years } & 21.063 & 20.739 & 21.048 & 20.705 \\ \text { Black race } & 0.121 & 0.169 & 0.120 & 0.165 \\ \text { Non-Black Hispanic ethnicity } & 0.197 & 0.310 & 0.205 & 0.323 \\ \text { Other race } & 0.171 & 0.251 & 0.173 & 0.252 \\ \text { Number of casualties } & 0.000 & 2.090 & 0.000 & 2.086 \\ \text { Across county moves } & 0.134 & 0.099 & 0.138 & 0.105 \\ \text { N } & 590334 & 211228 & 610862 & 216293\end{array}$

19-23 year olds in PUMAs potentially exposed 1-8 years ago

\begin{tabular}{lcccc} 
Age in years & 20.966 & 20.419 & 20.954 & 20.405 \\
Black race & 0.121 & 0.195 & 0.123 & 0.187 \\
Non-Black Hispanic ethnicity & 0.178 & 0.173 & 0.186 & 0.189 \\
Other race & 0.153 & 0.150 & 0.155 & 0.152 \\
Number of casualties & 0.000 & 2.024 & 0.000 & 1.947 \\
Across PUMA moves & 0.128 & 0.066 & 0.132 & 0.072 \\
N & 1274805 & 26745 & 1330599 & 28280 \\
\hline
\end{tabular}

Note: The primary sample consists of individuals ages 12-45 living in 327 counties from 1996-2008 ACS. An individual is exposed if they were exposed 1, 2, 3 or 4 years prior to the ACS survey year. A person is defined to have migrated if the person moved within state to a different county, to a different state, or abroad. 
Table 5: Determinants of migration regressions using ACS data

\begin{tabular}{|c|c|c|c|c|}
\hline & \multicolumn{2}{|c|}{ Sample of women } & \multicolumn{2}{|c|}{ Sample of men } \\
\hline & $\begin{array}{c}\text { Across county } \\
\text { moves }\end{array}$ & $\underset{\text { moves }}{\text { Across PUMA }}$ & $\begin{array}{c}\text { Across county } \\
\text { moves }\end{array}$ & $\underset{\text { moves }}{\text { Across PUMA }}$ \\
\hline \multicolumn{5}{|c|}{ 12-18 year olds potentially exposed $1-4$ years ago } \\
\hline Intensity & -0.00026 & 0.00198 & 0.00004 & 0.00029 \\
\hline & $(0.4866)$ & $(0.2616)$ & $(0.8922)$ & $(0.8621)$ \\
\hline $\mathrm{N}$ & 1231087 & 1061757 & 1300093 & 1117611 \\
\hline \multicolumn{5}{|c|}{$19-23$ year olds potentially exposed $1-8$ years ago } \\
\hline Intensity & 0.00013 & 0.00257 & -0.00026 & 0.00219 \\
\hline & $(0.6813)$ & $(0.3677)$ & $(0.4039)$ & $(0.3272)$ \\
\hline $\mathrm{N}$ & 801562 & 755400 & 827155 & 778104 \\
\hline
\end{tabular}

Note: The primary sample consists of individuals ages 12-45 living in 327 counties from 1996-2008 ACS. Covariates include indicators for age, race and ethnicity, county and year. Marginal effects of exposure 1, 2, 3 or 4 years ago are reported along with cluster-adjusted p-values in parentheses. Sum of effects denotes the sum of the marginal effects of exposure 1,2,3 and 4 years prior to the observation. 
Figure 1: Numbers of school shooting incidents and associated casualties over time

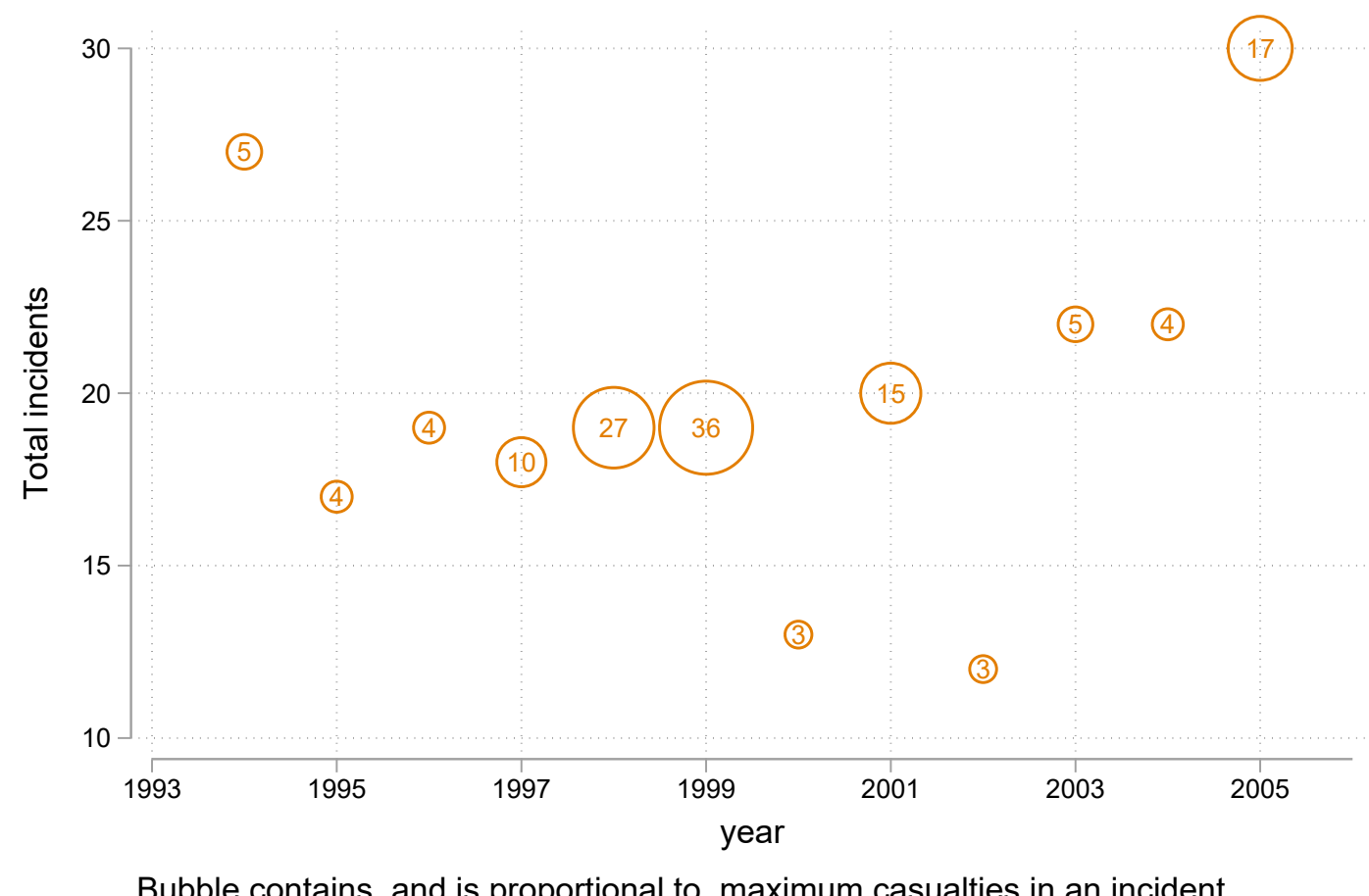

Bubble contains, and is proportional to, maximum casualties in an incident

Note: Includes school shootings from 1994-2005. 
Figure 2: Counties in which school shooting incidents occurred

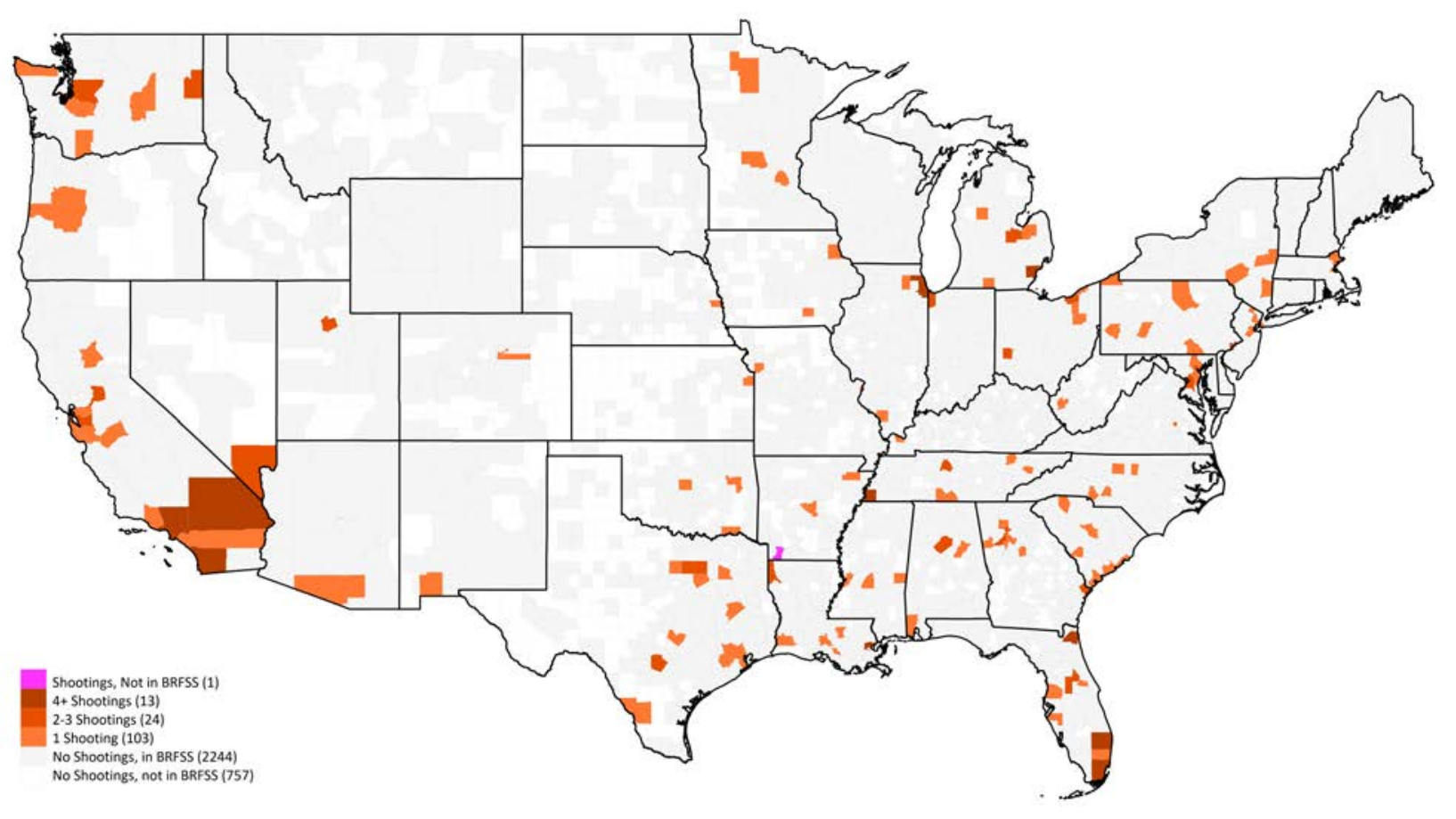

Note: Includes school shootings from 1994-2005. 
Figure 3: Estimates of effects of exposure to school shootings on outcomes among women

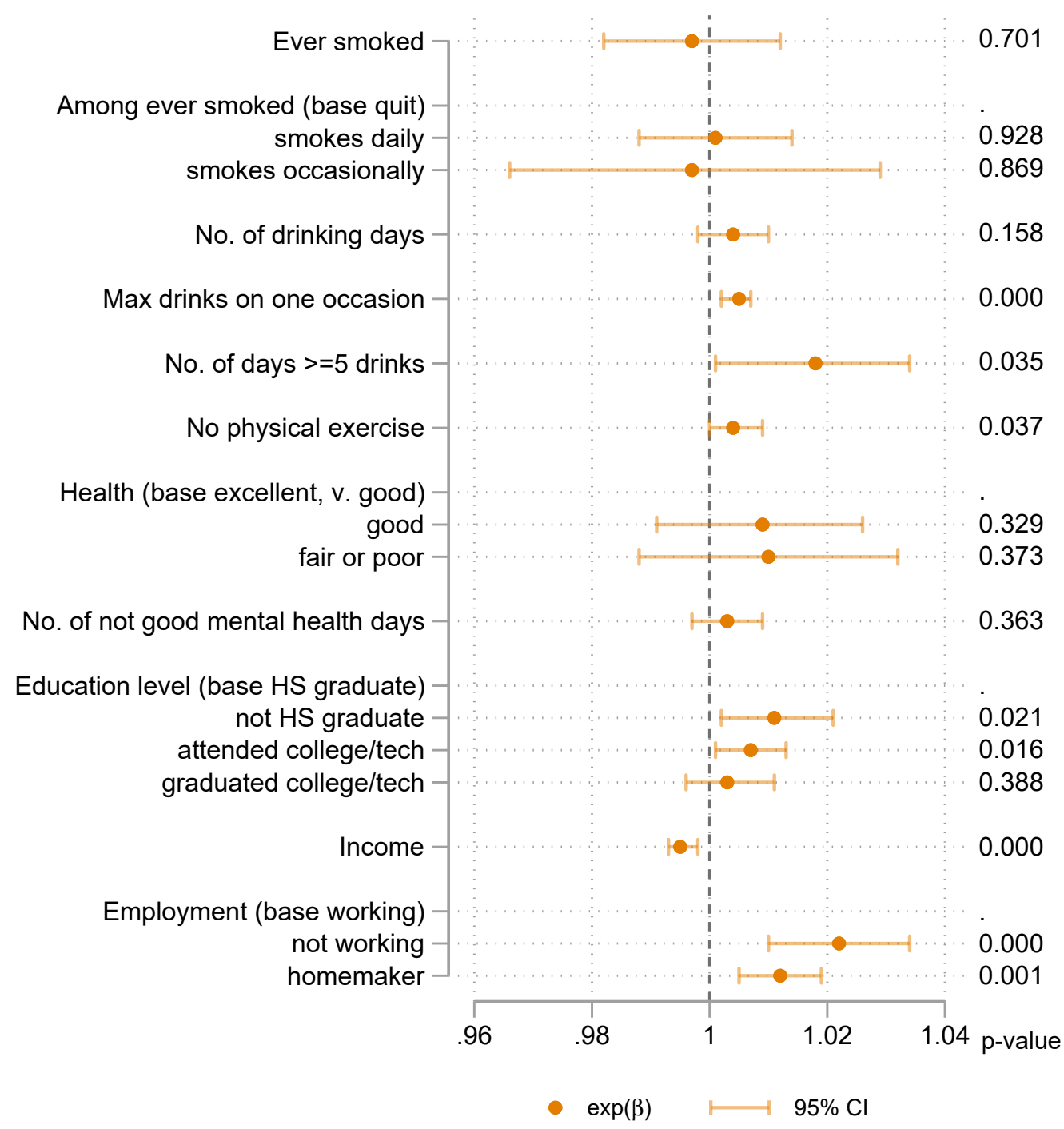

Note: The primary sample consists of individuals living in 1402 counties from 2003-2012 BRFSS. Covariates include indicators for age, race and ethnicity, county and year, and duration. Exponentiated coefficients along with cluster-adjusted p-values for statistical significance and associated $95 \%$ confidence intervals are reported. Confidence limits are bottom and top coded in $[0.95,1.05]$ to enhance readability. 
Figure 4: Estimates of effects of exposure to school shootings on outcomes among men

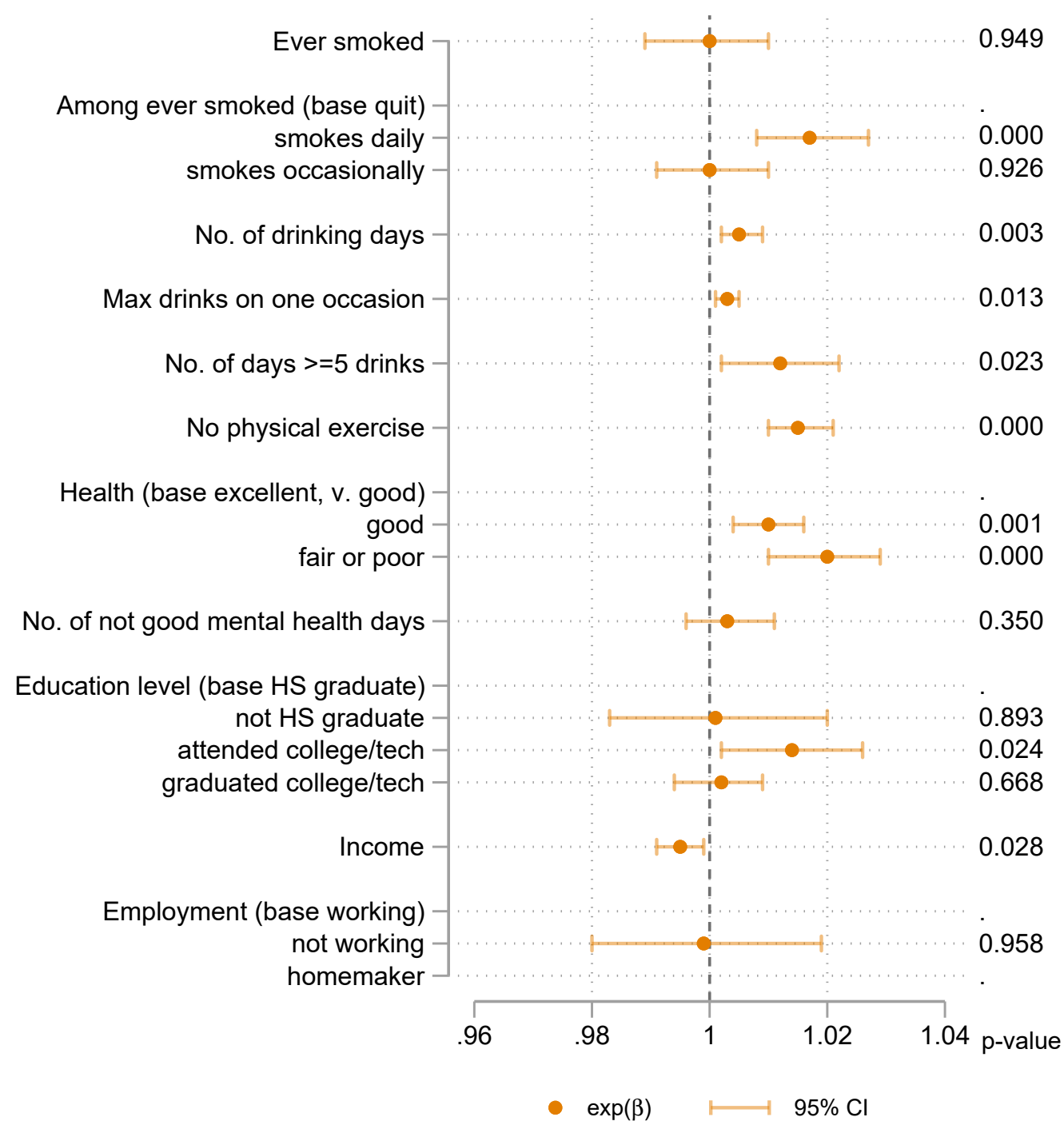

Note: The primary sample consists of individuals living in 1402 counties from 2003-2012 BRFSS. Covariates include indicators for age, race and ethnicity, county and year, and duration. Exponentiated coefficients along with cluster-adjusted p-values for statistical significance and associated $95 \%$ confidence intervals are reported. Confidence limits are bottom and top coded in $[0.95,1.05]$ to enhance readability. 
Figure 5: Estimates of effects of exposure to school shootings on outcomes among women in specification check samples and definitions

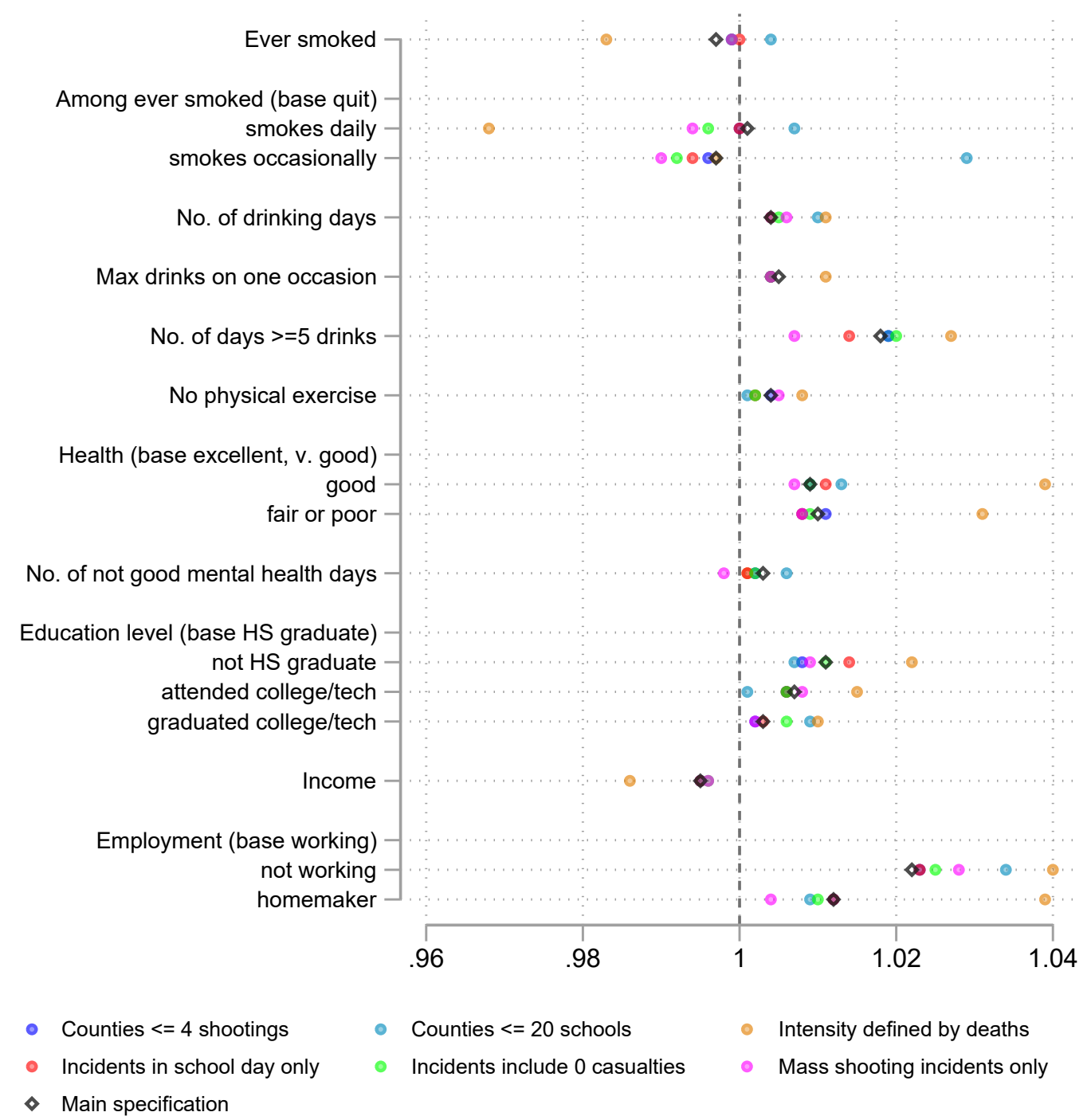

Note: The primary sample consists of individuals living in 1402 counties from 2003-2012 BRFSS. Covariates include indicators for age, race and ethnicity, county and year, and duration. Exponentiated coefficients are reported. 
Figure 6: Estimates of effects of exposure to school shootings on outcomes among men in specification check samples and definitions

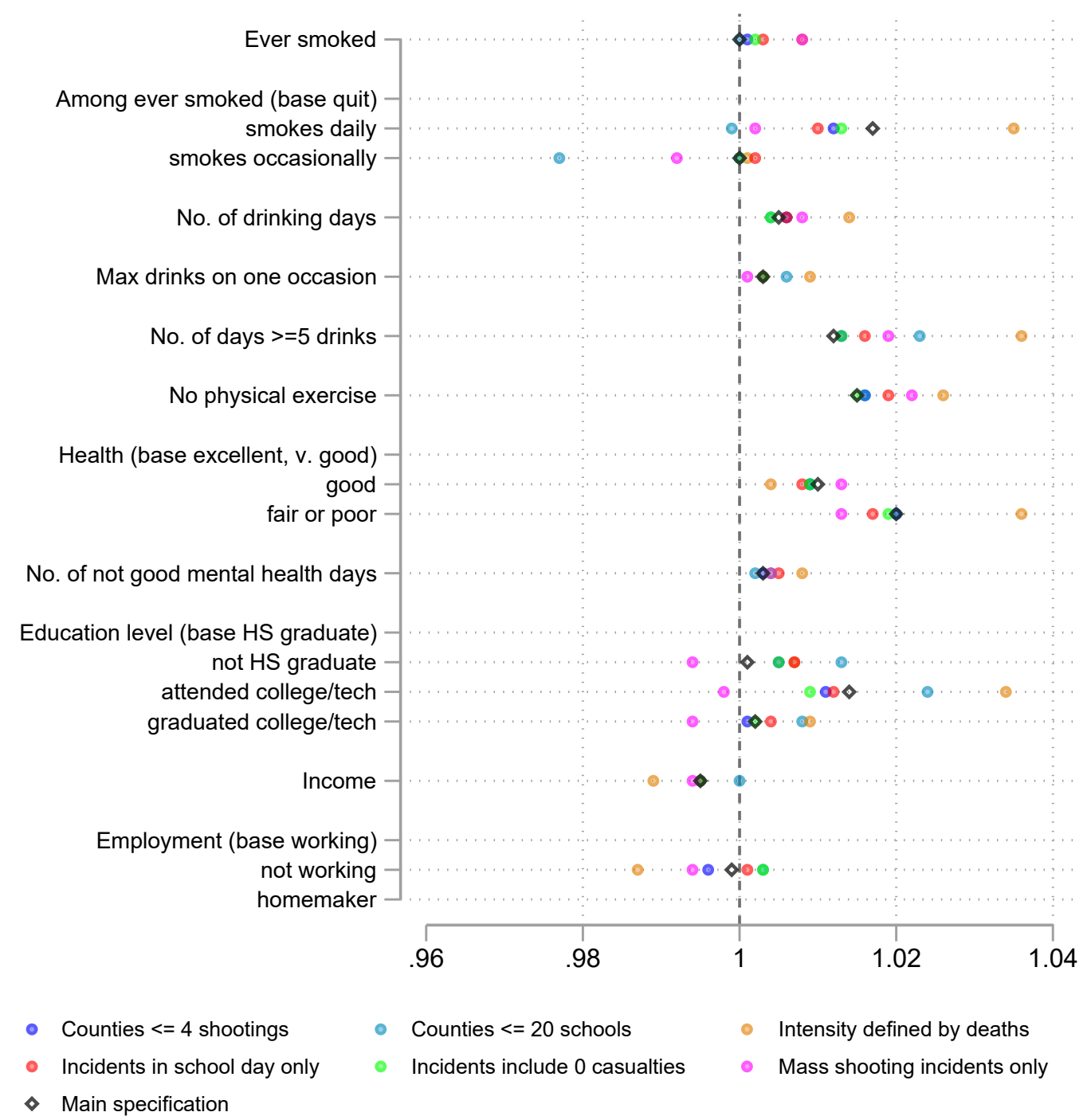

Note: The primary sample consists of individuals living in 1402 counties from 2003-2012 BRFSS. Covariates include indicators for age, race and ethnicity, county and year, and duration. Exponentiated coefficients are reported. 
Table A1: List of school shootings used in primary sample

\begin{tabular}{|c|c|c|}
\hline School & Location & Date of shooting \\
\hline Ensley High School & Birmingham, AL & $3 / 3 / 1994$ \\
\hline Blount High School & Prichard, AL & 9/27/1995 \\
\hline Talladega High School & Talladega, AL & $4 / 11 / 1996$ \\
\hline Huffman High School & Birmingham, AL & $8 / 3 / 2004$ \\
\hline Parker High School & Birmingham, AL & $11 / 15 / 2004$ \\
\hline Jacksonville High School & Sherwood, AR & 10/9/1996 \\
\hline Stamps High School & Stamps, AR & $12 / 15 / 1997$ \\
\hline Westside Middle School & Jonesboro, AR & $3 / 24 / 1998$ \\
\hline La Cima Middle School & Tucson, AZ & $4 / 10 / 2000$ \\
\hline Los Altos High School & Hacienda Heights, CA & $1 / 20 / 1994$ \\
\hline Hollywood High School & Los Angeles, CA & $9 / 7 / 1994$ \\
\hline Locke High School & Los Angeles, CA & 9/19/1994 \\
\hline Aliso Niguel High school & Aliso Veijo, CA & $10 / 31 / 1994$ \\
\hline Sacred Heart Middle School & Redlands, CA & $1 / 23 / 1995$ \\
\hline Jordan High School & Long Beach, CA & $2 / 2 / 1995$ \\
\hline Mid-Peninsula High School & Menlo Park, CA & $2 / 8 / 1996$ \\
\hline Colton High School & Colton, CA & $5 / 22 / 1996$ \\
\hline West Valley High School & Hemet, CA & 6/4/1996 \\
\hline John Marshall High School & Los Angeles, CA & $7 / 26 / 1996$ \\
\hline St. Bernard High School & Playa Del Rey, CA & $10 / 4 / 1996$ \\
\hline Highlands High School & Sacramento, CA & $11 / 27 / 1996$ \\
\hline Maria Del Rey Junior High School & Mar Vista, CA & $4 / 3 / 1997$ \\
\hline John Marshall High School & Los Angeles, CA & $4 / 28 / 1997$ \\
\hline McClymonds High School & Oakland, CA & $10 / 20 / 1997$ \\
\hline John Glenn High School & Norwalk, CA & $10 / 22 / 1997$ \\
\hline Culver City High School & Los Angeles, CA & 4/23/1998 \\
\hline Rialta High School & Rialto, CA & $5 / 21 / 1998$ \\
\hline Washington Middle School & Pasadena, CA & $5 / 27 / 1998$ \\
\hline Herbert Hoover High School & Glendale, CA & $9 / 11 / 1998$ \\
\hline Santa Teresa High School & San Jose, CA & 9/9/1999 \\
\hline San Fernando High School & Pacoima, CA & 10/21/1999 \\
\hline Granada Hills High School & Los Angeles, CA & $12 / 1 / 2000$ \\
\hline Junipero Serra High School & San Diego, CA & $12 / 1 / 2000$ \\
\hline Richmond High School & Richmond, CA & $12 / 7 / 2000$ \\
\hline Balboa High School & San Francisco, CA & $1 / 3 / 2001$ \\
\hline Hueneme High School & Oxnard, CA & $1 / 10 / 2001$ \\
\hline Hoover High School & San Diego, CA & $3 / 2 / 2001$ \\
\hline Santana High School & Santee, CA & $3 / 5 / 2001$ \\
\hline Granite Hills High School & El Cajon, CA & $3 / 22 / 2001$ \\
\hline Belmont High School & Los Angeles, CA & $7 / 30 / 2001$ \\
\hline Redondo Union High School & Redondo Beach, CA & $10 / 26 / 2001$ \\
\hline Gardena High School & Los Angeles, CA & $2 / 6 / 2002$ \\
\hline Rolling Hills Middle School & Watsonville, CA & $3 / 30 / 2003$ \\
\hline Rio Cazadero High School & Sacramento, CA & $10 / 1 / 2003$ \\
\hline Pomona High School & Pomona, CA & $1 / 15 / 2004$ \\
\hline Saledad Enrichment Action Charter High School & Los Angeles, CA & $3 / 5 / 2004$ \\
\hline East Campus Educational Center & Merced, CA & $5 / 12 / 2004$ \\
\hline Castlemont High School & Oakland, CA & $6 / 9 / 2004$ \\
\hline Biggs High School & Biggs, CA & $10 / 15 / 2004$ \\
\hline Locke High School & Los Angeles, CA & $3 / 17 / 2005$ \\
\hline
\end{tabular}


San Gorgonio High School

Columbine High School

Thomas Jefferson High School

Eastern High School

Eliot Junior High School

Cardozo Senior High School

Winston Education Center

McKinley High School

Cardozo High School

Anacostia High School

Ballou Senior High School

North Miami High School

Palm Beach Gardens High School

Lake Worth High School

Tavares Middle School

Lake Howell High School

Conniston Middle School

First Coast High School

Northwestern High School

Lincoln Middle School

Ribault High School

North Miami Senior High School

Stranahan High School

Leesburg High School

North Miami High School

Ridgewood High School

Lake Worth Middle School

Terry Parker High School

Sojourner Truth High School

Santiago High School

Etowah High School

Jenkins High School

Dekalb Alternative School

Central High School

Martin Luther King Jr. Middle School

Heritage High School

Jasper County High School

Beach High School

McNair High School

Morrow High School

Ottumwa High School

Clayton Ridge High School

Hubbard High School

Ombudsman Educational Service Center

Niles West High School

Roosevelt High School

Englewood High School

Carbondale Community High School

Proviso East High School

Bowen High School

Harlan Community Academy High School

Wallace High School

Lew Wallace High School

Olathe North High School
San Bernardino, CA 10/19/2005

Littleton, CO 4/20/1999

Denver, CO 5/2/2000

Washington, DC 3/9/1994

Washington, DC 4/19/1994

Washington, DC $\quad 1 / 6 / 1995$

Washington, DC 1/19/1996

Washington, DC 4/15/1996

Washington, DC $\quad 4 / 1 / 2003$

Washington, DC 10/30/2003

Washington, DC 2/2/2004

North Miami, FL 5/2/1994

Palm Beach Gardens, FL 1/10/1995

Lake Worth, FL 6/14/1995

Tavares, FL 9/29/1995

Casselberry, FL 10/23/1995

West Palm Beach, FL 1/27/1997

Jacksonville, FL 2/20/1997

Miami, FL 5/13/1997

Palmetto, FL 10/15/1997

Jacksonville, FL 11/7/1997

Miami, FL 5/1/1998

Ft. Lauderdale, FL $\quad 5 / 29 / 1998$

Leesburg, FL 9/30/1998

Miami, FL 9/30/1998

New Port Richey, FL $\quad 1 / 19 / 2000$

Lake Worth, FL $\quad 5 / 26 / 2000$

Jacksonville, FL 11/19/2004

Jacksonville, FL $\quad 9 / 2 / 2005$

Garden Grove, FL 12/6/2005

Cherokee, GA 3/25/1994

Savannah, GA 2/22/1996

Decatur, GA 9/25/1996

Carrollton, GA 1/8/1999

Atlanta, GA $\quad 4 / 22 / 1999$

Conyers, GA 5/20/1999

Monticello, GA 8/25/1999

Savannah, GA $\quad 3 / 10 / 2000$

Atlanta, GA 2/4/2005

Morrow, GA 8/19/2005

Ottumwa, IA 7/25/1994

Guttenberg, IA 3/18/2003

Chicago, IL 10/17/1994

Elgin, IL

Skokie, IL

Chicago, IL

Chicago, IL

Maywood, IL 8/30/2004

Chicago, IL 2/8/2005

Chicago, IL 9/13/2005

Gary, IN 10/10/1997

Gary, IN 3/30/2001

Olathe, KS 9/14/1995 
Heath High School

Scotlandville Middle School

Carter G. Woodson Middle School

Abramson High School

Fair Park High School

John McDonogh High School

Gathway Christian Academy

Booker T. Washington High School

La Grange High School

O Perry Walker High School

Booker T. Washington High School

Charlestown High School

Newburyport High School

Largo High School

Lake Clifton Eastern High School

Largo High School

Lake Clifton Eastern High School

Benjamin Tasker Middle School

Randallstown High School

Thurgood Marshall High School

Annapolis High School

Osborn High School

Redford High School

Pershing High School

Reed City High School

Coldwater High School

Osborn High School

Benito Juarez Academy

Caro Learning Center

Osborn High School

Saginaw High School

Saginaw High School

Central High School

Minneapolis North High School

Rocori High School

Red Lake Senior High School

Beaumont High School (bus)

Sumner High School

St. James Catholic School

Pearl High School

Northeast High School

Vicksburg High School

Grimsley High School

North Stanley High School

Grey Culbreth Middle School

East Mecklenburg High School

South High School

Lakeland Regional High School

Hoboken High School

Lincoln High School

Colonia High School

Weequahic High School

Deming Middle School

Swainston Middle School
West Paducah, KY

$12 / 1 / 1997$

Baton Rouge, LA

4/22/1999

$9 / 26 / 2000$

$4 / 26 / 2002$

$4 / 14 / 2003$

$4 / 14 / 2003$

$2 / 20 / 2004$

$9 / 12 / 2004$

$12 / 13 / 2004$

$3 / 17 / 2005$

$5 / 24 / 2005$

$9 / 17 / 2003$

$10 / 7 / 2004$

$4 / 8 / 1994$

$1 / 17 / 2001$

$3 / 6 / 2001$

$9 / 21 / 2001$

$10 / 7 / 2002$

$5 / 7 / 2004$

$10 / 21 / 2004$

$10 / 28 / 2005$

$2 / 8 / 1994$

$3 / 27 / 1995$

$3 / 17 / 1997$

$2 / 25 / 1998$

$3 / 25 / 1998$

$2 / 2 / 2001$

$10 / 26 / 2001$

$11 / 12 / 2001$

$12 / 2 / 2002$

$9 / 24 / 2005$

$10 / 20 / 2005$

$12 / 6 / 2005$

$10 / 5 / 2000$

$9 / 24 / 2003$

$3 / 21 / 2005$

2/29/1996

$10 / 14 / 1996$

$11 / 7 / 2002$

$10 / 1 / 1997$

$3 / 21 / 2003$

$9 / 10 / 2003$

$10 / 12 / 1994$

$3 / 11 / 1996$

$3 / 30 / 1998$

$11 / 13 / 2003$

$1 / 26 / 2000$

$5 / 25 / 1994$

2/12/1998

$10 / 29 / 2002$

$12 / 22 / 2003$

$7 / 18 / 2005$

$11 / 19 / 1999$

3/19/1996 
Clark High School

Sweet Home High School

Thomas A. Edison Vocational and Technical High School

Crown Heights High School

City-as-School High School

Hancock Middle High School

Harry S. Truman High School

Martin Luther King, Jr. High School

Columbia High School

New Utrecht High School

Arlington High School

Samula Tilden High School

Wickliffe Middle School

Dunbar High School

Timken Senior High School

John Marshall High School

Kenmore High School

Colonel White High School

Daniel E. Morgan Elementary School

Fort Gibson Middle School

Hugo High School

Douglas High School

Lebanon Union High School

Thurston High School

Girard High School

Martin Luther King High School

Martin Luther King High School

Bishop Neumann High School

Red Lion Area Junior High School

Forest Hills High School

Rock L. Butler Middle School

Murrell Dobbins Vocational-Technical High School

Carrick High School

Eau Claire High School

Spartanburg High School

Goose Creek High School

Blackville-Hilda High School

Battery Creek High School

John Bartram High School

J.T. Moore Middle School

Cypress Junior High School

Richland High School

East High School

Lincoln County High School

Maplewood Comprehensive High School

Fairly High School

East High School

Maury Middle School

Campbell County High School

Kennard High School

McNeil High School

Memorial Middle School

Richland High School

Dickinson High School
Las Vegas, NV

Albany, NY

New York, NY

New York, NY

New York, NY

Hancock, NY

New York, NY

New York, NY

East Greenbush, NY

Brooklyn, NY

Poughkeepsie, NY

New York, NY

Wickliffe, $\mathrm{OH}$

Dayton, $\mathrm{OH}$

Canton, $\mathrm{OH}$

Cleveland, $\mathrm{OH}$

Akron, $\mathrm{OH}$

Dayton, $\mathrm{OH}$

Cleveland, $\mathrm{OH}$

Fort Gibson, OK

Hugo, OK

Oklahoma City, OK

Lebanon, OR

Springfield, OR

Girard, PA

Philadelphia, PA

Philadelphia, PA

Williamsport, PA

Red Lion, PA

Johnstown, PA

Wellsboro, PA

North Philadelphia, PA

Pittsburgh, PA

Columbia, SC

Spartanburg, SC

Charleston, SC

Blackville, SC

Beaufort, SC

Philadelphia City, SD

Nashville, TN

Memphis, TN

Lynnville, TN

Memphis, TN

Fayetteville, TN

Nashville, TN

Memphis, TN

Memphis, TN

Dandridge, TN

Jacksboro, TN

Kennard, TX

Austin, TX

Laredo, TX

North Richland Hills, TX

Dickinson, TX
$10 / 11 / 1999$

$9 / 8 / 1994$

$11 / 28 / 1995$

$1 / 8 / 1997$

$4 / 30 / 1997$

$11 / 30 / 1998$

$1 / 14 / 1999$

$1 / 15 / 2002$

$2 / 9 / 2004$

$3 / 21 / 2005$

$6 / 8 / 2005$

$10 / 14 / 2005$

$11 / 7 / 1994$

$5 / 20 / 1997$

$7 / 26 / 2000$

$4 / 25 / 2001$

$10 / 7 / 2003$

$2 / 13 / 2004$

$4 / 29 / 2005$

$12 / 6 / 1999$

$4 / 6 / 2000$

$12 / 4 / 2003$

$9 / 22 / 1994$

$5 / 21 / 1998$

$1 / 2 / 1996$

$11 / 3 / 1998$

$10 / 26 / 1999$

$3 / 7 / 2001$

$4 / 24 / 2003$

$5 / 13 / 2003$

$6 / 4 / 2003$

$1 / 5 / 2005$

$3 / 16 / 2005$

$1 / 24 / 1994$

2/18/1994

$3 / 15 / 1994$

$10 / 12 / 1995$

$11 / 16 / 2004$

10/4/1999

$4 / 21 / 1994$

9/12/1995

$11 / 15 / 1995$

$1 / 26 / 1996$

$5 / 19 / 1998$

$3 / 9 / 2005$

$3 / 24 / 2005$

$3 / 30 / 2005$

$8 / 25 / 2005$

$11 / 8 / 2005$

$1 / 21 / 1994$

$4 / 5 / 1994$

$8 / 29 / 1995$

1/21/1999

$11 / 17 / 1999$ 
Kleb Intermediate School

Ennis High School

Ousley Junior High School

Brock High School

Page Middle School

Greenhill Middle School

Hightower High School

Canton High School

Berkner High School

Irving Middle School

Taylorsville High School

West High School

John F. Kennedy High School

Marshall High School

Armstrong High School

Whitman Middle School

Ballard High School

Stadium High School

Garfield High School

Frontier Middle School

Wind River Middle School

Lewis and Clark High School

Crescent Junior-Senior High School

Lakeside High School

Guyan Valley High School
Houston, TX

Ennis, TX

Arlington, TX

Brock, TX

San Antonio, TX

Addison, TX

Sugarland, TX

Canton, TX

Richardson, TX

San Antonio, TX

Taylorsville, UT

Salt Lake City, UT

Richmond, VA

Fairfax, VA

Richmond, VA

Seattle, WA

Seattle, WA

Tacoma, WA

Seattle, WA

Moses Lake, WA

Carson, WA

Spokane, WA

Joyce, WA

Spokane, WA

Branchland, WV
$4 / 2 / 2001$

$5 / 15 / 2001$

$6 / 7 / 2001$

$2 / 1 / 2002$

$10 / 4 / 2002$

$4 / 16 / 2003$

$11 / 8 / 2003$

$4 / 7 / 2005$

$5 / 14 / 2005$

$11 / 16 / 2005$

$10 / 12 / 2001$

$5 / 24 / 2004$

$10 / 30 / 1995$

$2 / 27 / 1998$

$6 / 15 / 1998$

$1 / 31 / 1994$

$3 / 23 / 1994$

$11 / 15 / 1994$

$1 / 12 / 1995$

$2 / 2 / 1996$

$12 / 12 / 2002$

$9 / 22 / 2003$

$3 / 17 / 2004$

$12 / 9 / 2004$

$10 / 26 / 1999$

Source: K-12 School Shootings Database 
Table A2: Characteristics of casualties and duration in samples and definitions used in specification checks

\begin{tabular}{lcccccccc}
\hline Change from main specification & \multicolumn{2}{c}{ Sample size } & \multicolumn{3}{c}{ Percent } & \multicolumn{2}{c}{ Intensity } & \multicolumn{3}{c}{ Years since exposure } \\
& female & male & exposed & $P_{50}$ & $P_{95}$ & $P_{50}$ & Min & Max \\
\hline Shorten shooting period to 1995-2004 & 197426 & 122519 & 6.3 & 2 & 4 & 12 & 6 & 17 \\
Extend shooting period to 1993-2006 & 197426 & 122519 & 10.5 & 1 & 5 & 13 & 6 & 19 \\
Covariate balancing weights applied & 197426 & 122519 & 50.0 & 1 & 5 & 12 & 6 & 18 \\
Restrict to counties (1396) with $\leq$ 4 incidents & 190682 & 118325 & 6.5 & 1 & 3 & 12 & 6 & 18 \\
Restrict to counties (1239) with $\leq$ 20 schools & 122365 & 74915 & 2.4 & 1 & 8 & 12 & 6 & 18 \\
Divide intensity by the number of schools & 197426 & 122519 & 8.2 & .033 & .158 & 12 & 6 & 18 \\
Incidents during the school day only & 197426 & 122519 & 5.0 & 2 & 3 & 12 & 6 & 17 \\
Incidents include those with 0 casualties & 197426 & 122519 & 6.8 & 3 & 5 & 12 & 6 & 17 \\
\hline
\end{tabular}

Note: The primary sample consists of individuals ages 23-32 living in 1402 counties from 2003-2012 BRFSS. The samples used in specification checks also span the same counties and years unless otherwise specified. $P_{50}$ is the median among those exposed. $P_{95}$ is the $95^{\text {th }}$ percentile value in the sample among those exposed. Min and Max denote the minimum and maximum sample values among those exposed. The numbers of counties in county-restricted samples are reported in parentheses. 
Table A3: Regressions of county-level unemployment and homicide rates on exposure to school shootings

\begin{tabular}{lcccc}
\hline & \multicolumn{2}{c}{ Sample of women } & \multicolumn{2}{c}{ Sample of men } \\
\multirow{2}{*}{ Intensity } & Unemployment rate & Homicide rate & Unemployment rate & Homicide rate \\
& -0.00710 & 0.00020 & -0.00561 & 0.00016 \\
$N$ & $(0.4075)$ & $(0.1724)$ & $(0.5076)$ & $(0.1812)$ \\
\hline
\end{tabular}

Note: The primary sample consists of individuals living in 1402 counties from 2003-2012 BRFSS. Covariates include indicators for age, race and ethnicity, county and year, and duration. Cluster-adjusted p-values are in parentheses. 
Table A4: Determinants of migration regressions using ACS data

\begin{tabular}{|c|c|c|c|c|}
\hline & \multicolumn{2}{|c|}{ Sample of women } & \multicolumn{2}{|c|}{ Sample of men } \\
\hline & $\begin{array}{l}\text { Across county } \\
\text { moves }\end{array}$ & $\underset{\text { moves }}{\text { Across PUMA }}$ & $\begin{array}{c}\text { Across county } \\
\text { moves }\end{array}$ & $\underset{\text { moves }}{\text { Across PUMA }}$ \\
\hline \multicolumn{5}{|c|}{ 12-18 year olds potentially exposed $0-3$ years ago } \\
\hline Intensity & -0.00054 & 0.00209 & 0.00002 & -0.00145 \\
\hline & $(0.1358)$ & $(0.2232)$ & $(0.9605)$ & $(0.3702)$ \\
\hline $\mathrm{N}$ & 1231087 & 1061757 & 1300093 & 1117611 \\
\hline \multicolumn{5}{|c|}{ 19-23 year olds potentially exposed $0-7$ years ago } \\
\hline Intensity & 0.00019 & 0.00220 & 0.00016 & 0.00353 \\
\hline & $(0.6371)$ & $(0.3170)$ & $(0.6282)$ & $(0.0950)$ \\
\hline $\mathrm{N}$ & 801562 & 755400 & 827155 & 778104 \\
\hline
\end{tabular}

Note: The primary sample consists of individuals ages 12-45 living in 327 counties from 1996-2008 ACS. Covariates include indicators for age, race and ethnicity, county and year. Marginal effects of exposure 1, 2, 3 or 4 years ago are reported along with cluster-adjusted p-values in parentheses. Sum of effects denotes the sum of the marginal effects of exposure 1,2, 3 and 4 years prior to the observation. 
Figure A1: Ages of BRFSS respondents in each survey year who would be potentially exposed to school shootings in three illustrative years

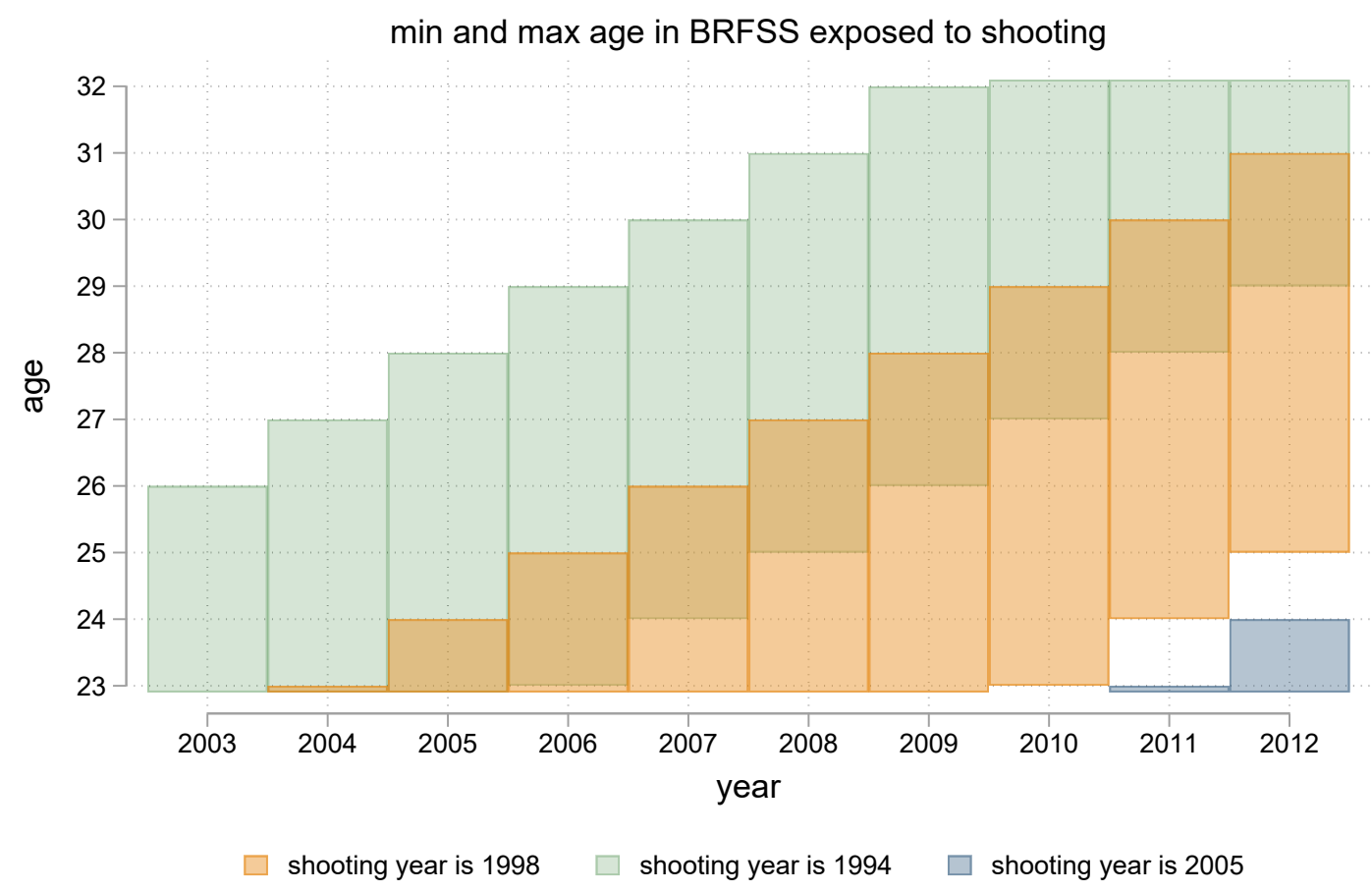

Note: The figure shows the range of ages that can be exposed to shootings that occurred in 1994, 2012 and 2005 in each year of the BRFSS data. The earliest shooting year, 1994, contributes 23-26 year old individuals exposed to shootings in 2003 through 29-32 year old individuals exposed in 2012. The latest shooting year only contributes exposed individuals in 2011 and 2012. 
Figure A2: Estimates of effects of exposure to school shootings on outcomes among women stratified by duration since exposure

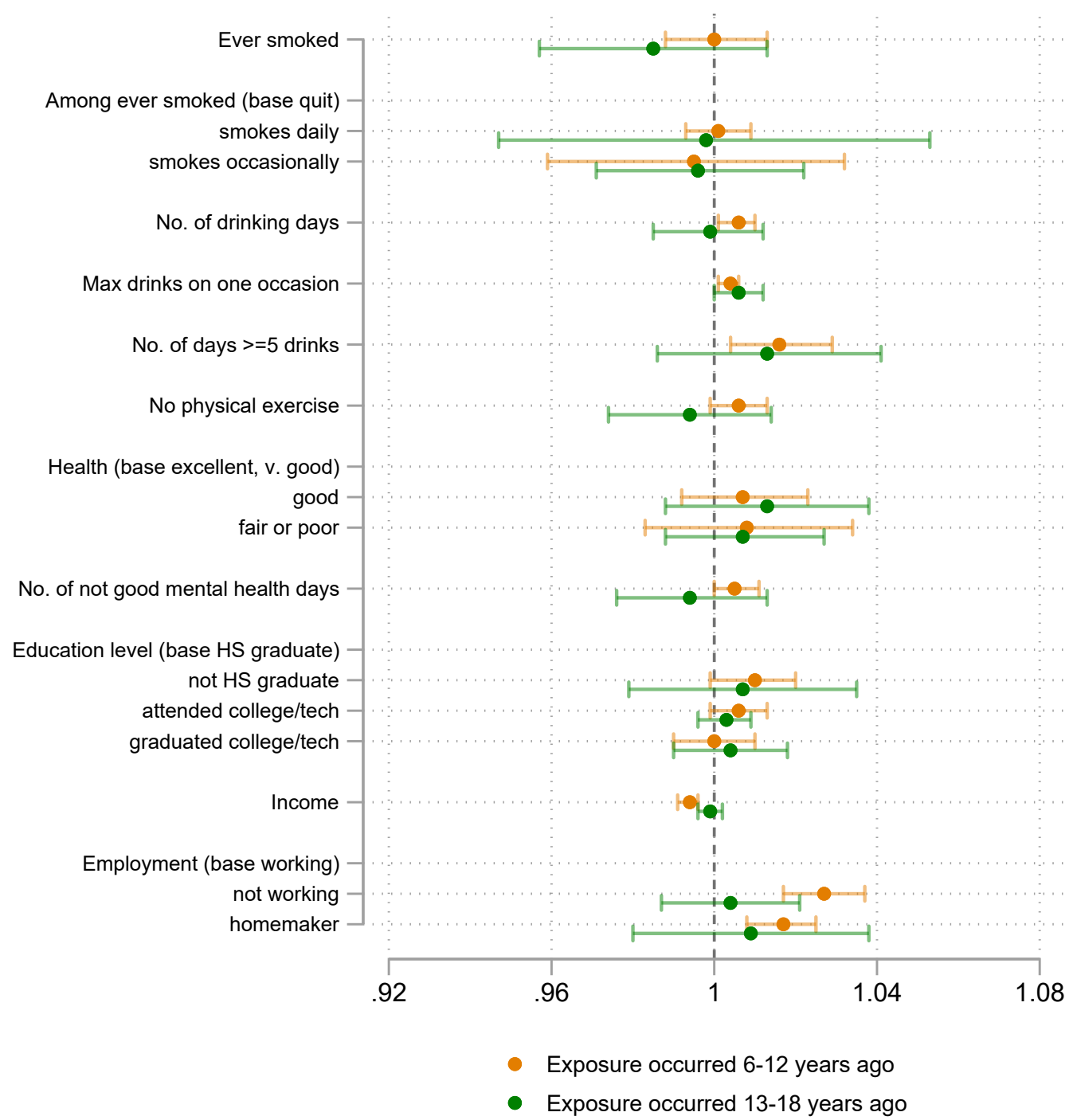

Note: The primary sample consists of individuals living in 1402 counties from 2003-2012 BRFSS. Covariates include indicators for age, race and ethnicity, county and year, and duration. Exponentiated coefficients along with cluster-adjusted p-values for statistical significance and associated $95 \%$ confidence intervals are reported. Confidence limits are bottom and top coded in $[0.9,1.1]$ to enhance readability. One stratum considers incidents that occurred 6-12 years prior to the survey. The other stratum considers incidents that occurred 13-18 years prior to the survey. 
Figure A3: Estimates of effects of exposure to school shootings on outcomes among men stratified by duration since exposure

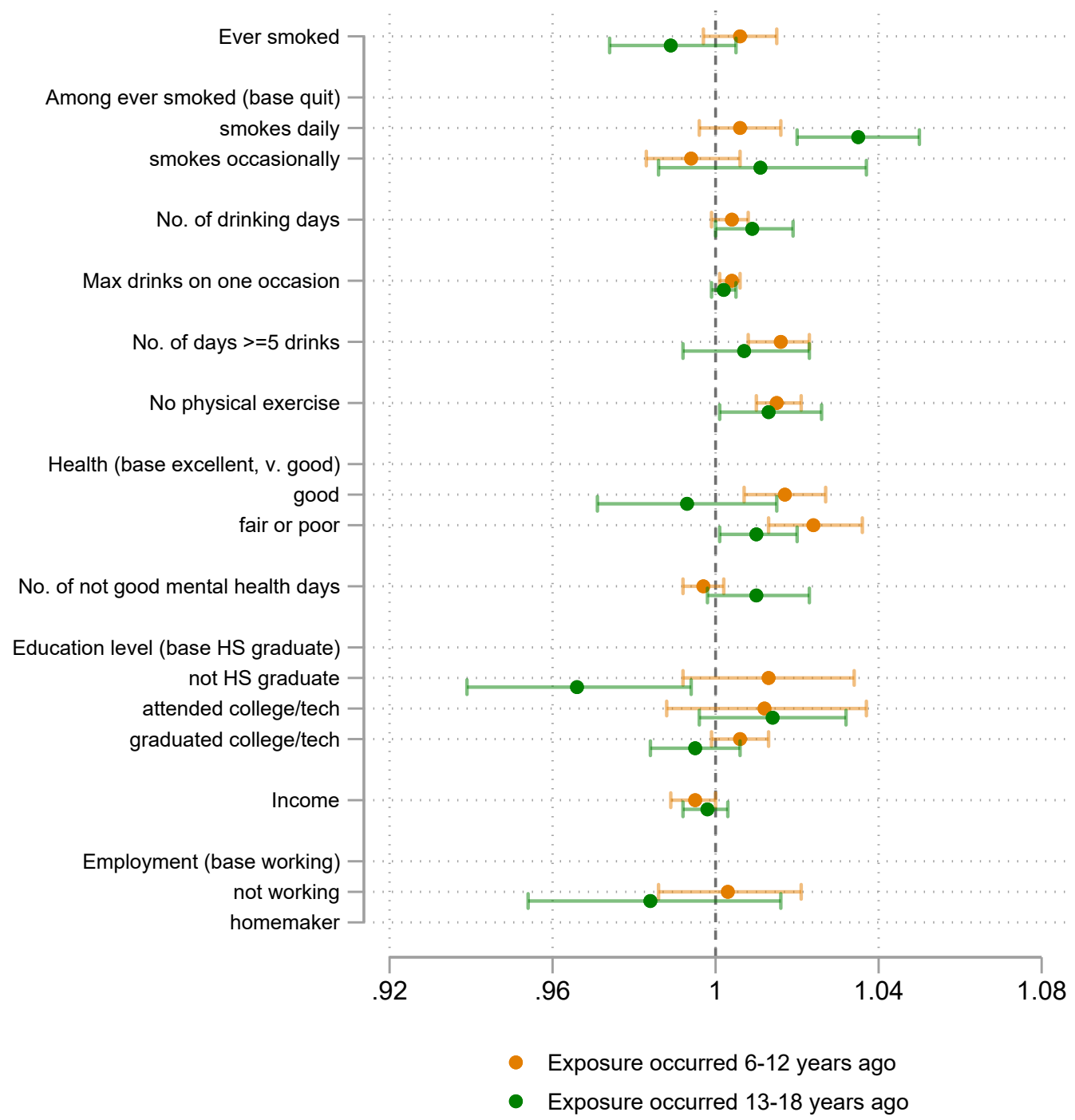

Note: The primary sample consists of individuals living in 1402 counties from 2003-2012 BRFSS. Covariates include indicators for age, race and ethnicity, county and year, and duration. Exponentiated coefficients along with cluster-adjusted p-values for statistical significance and associated $95 \%$ confidence intervals are reported. Confidence limits are bottom and top coded in $[0.9,1.1]$ to enhance readability. One stratum considers incidents that occurred 6-12 years prior to the survey. The other stratum considers incidents that occurred 13-18 years prior to the survey. 
Figure A4: Estimates of effects of exposure to school shootings on outcomes among women in specification check samples and definitions

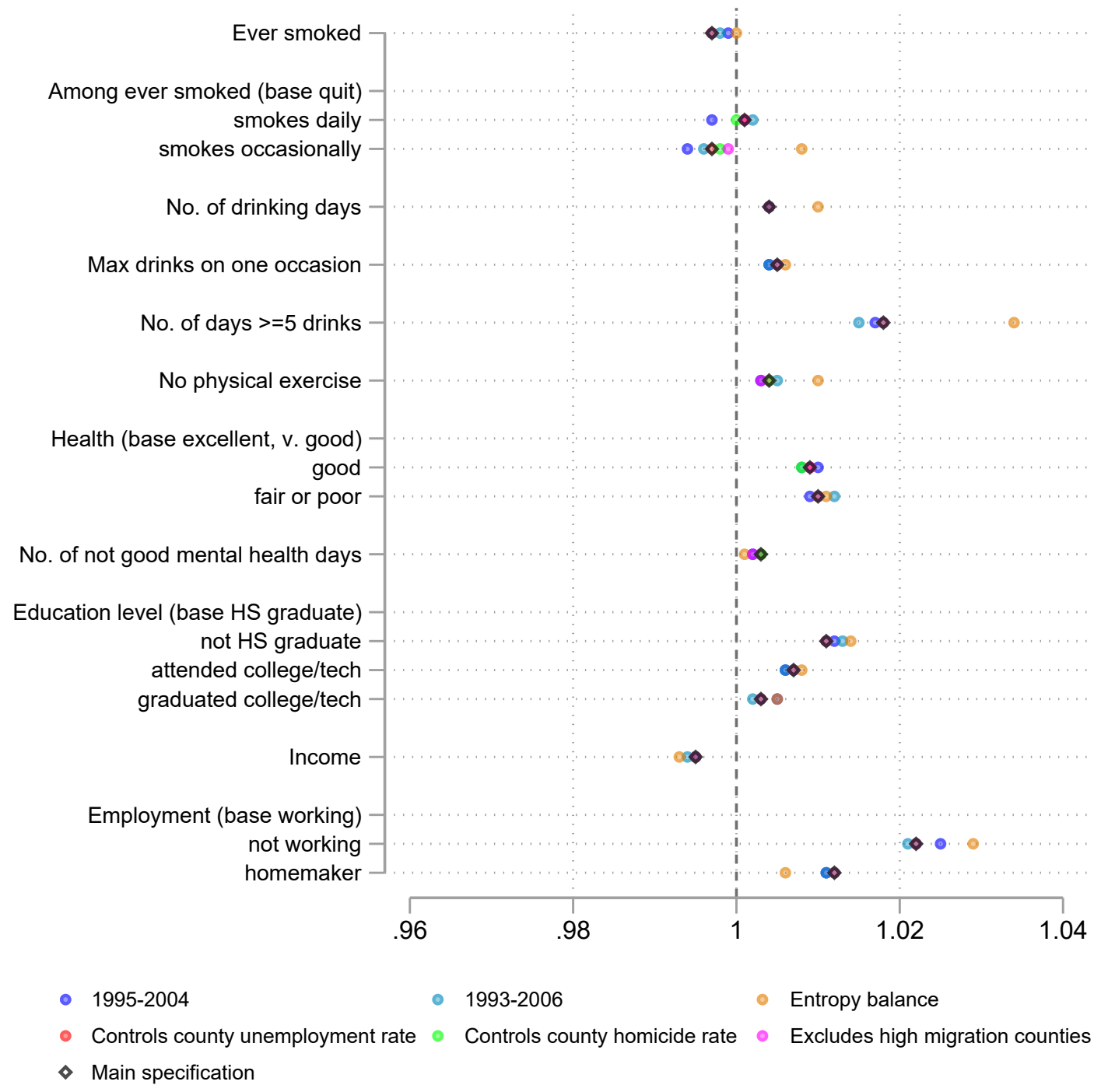

Note: The primary sample consists of individuals living in 1402 counties from 2003-2012 BRFSS. Covariates include indicators for age, race and ethnicity, county and year, and duration. Exponentiated coefficients are reported. 
Figure A5: Estimates of effects of exposure to school shootings on outcomes among men in specification check samples and definitions

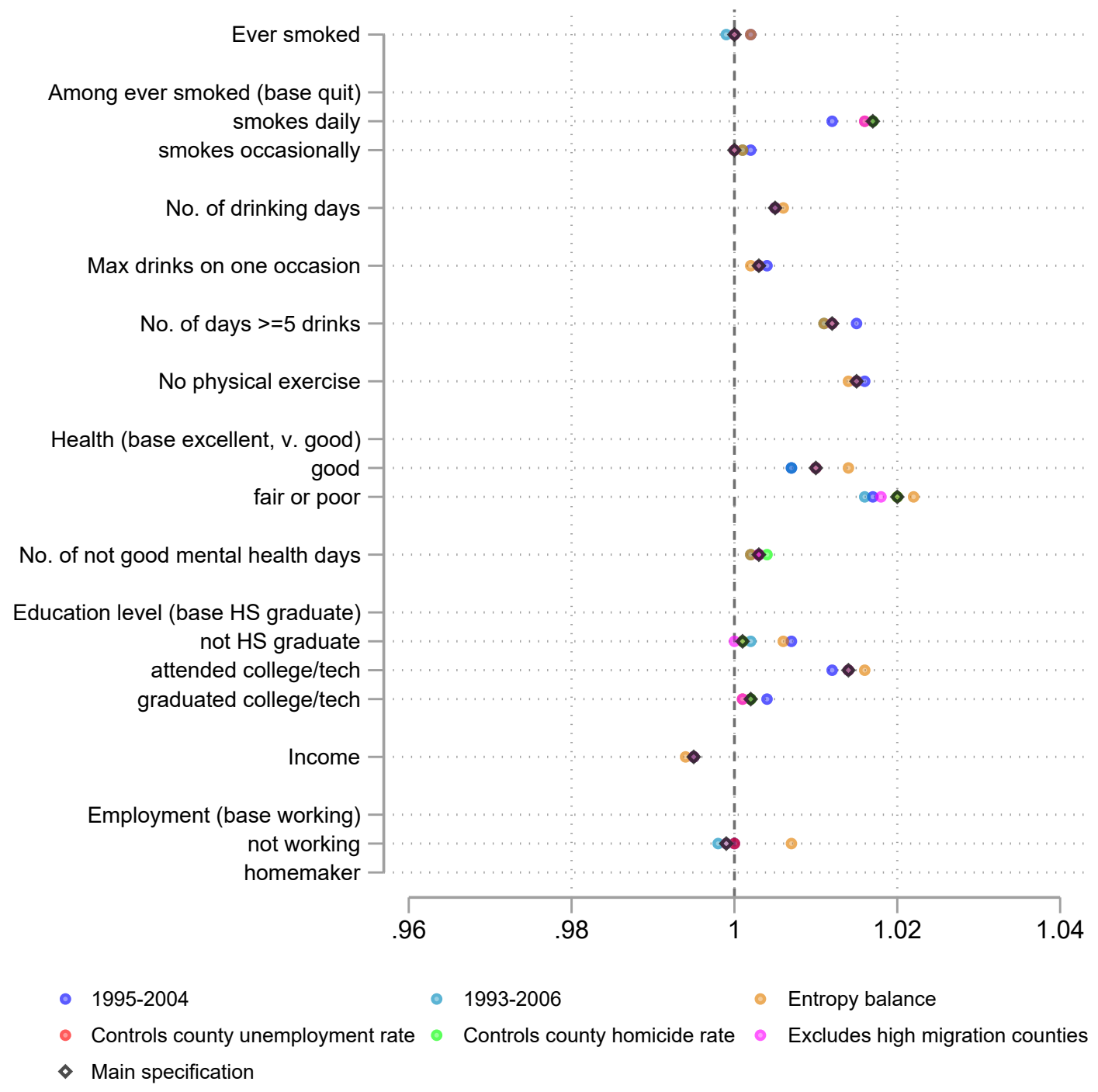

Note: The primary sample consists of individuals living in 1402 counties from 2003-2012 BRFSS. Covariates include indicators for age, race and ethnicity, county and year, and duration. Exponentiated coefficients are reported. 
Figure A6: Estimates of effects of exposure to school shootings on outcomes with placebo treatment assigned to individuals 4-10 years old at the time of the shooting incident

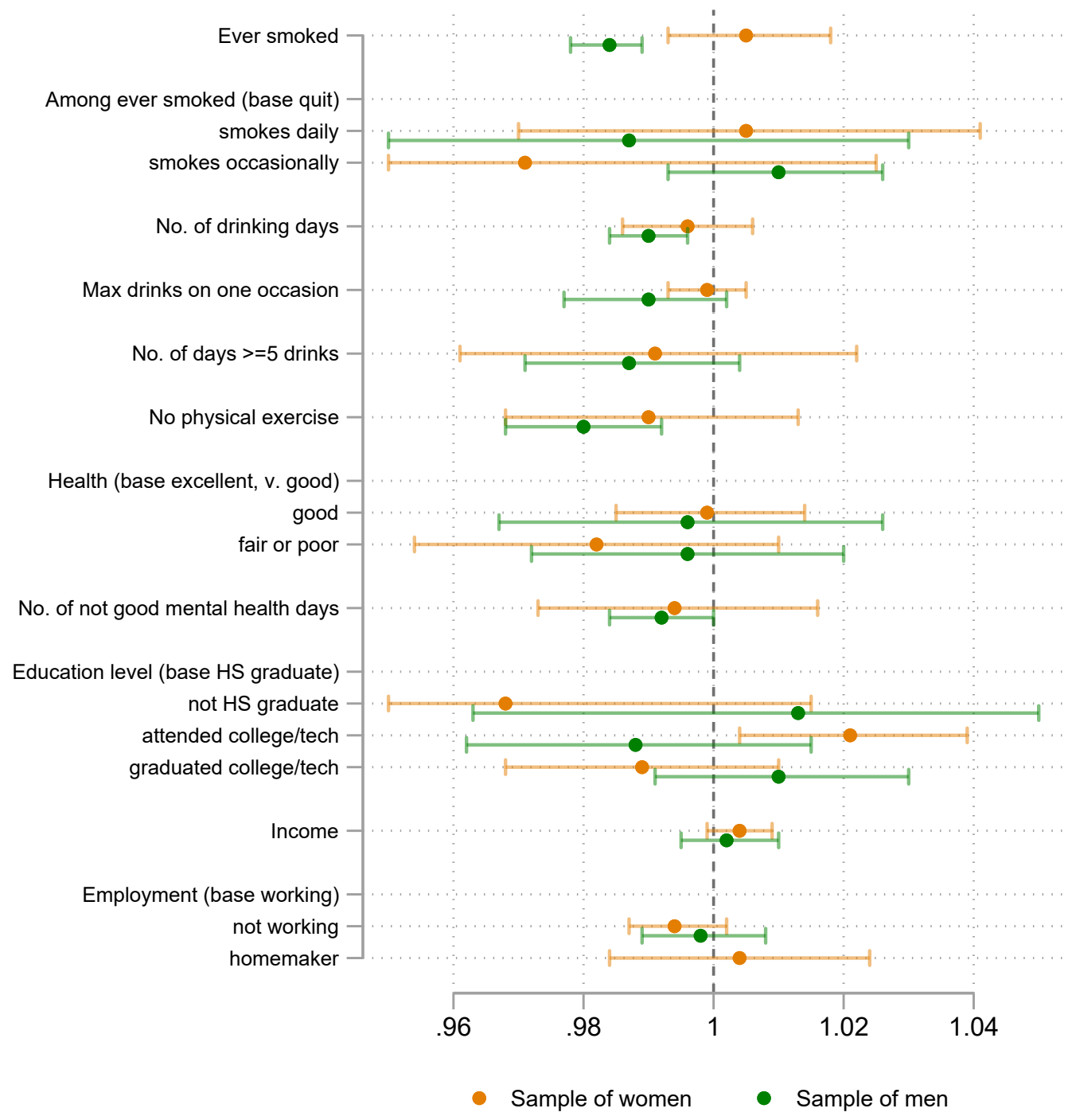

Note: The sample consists of individuals ages 20-29 years old living in 1402 counties from 2003-2012 BRFSS. Covariates include indicators for age, race and ethnicity, county and year, and duration. Exponentiated coefficients along with cluster-adjusted p-values for statistical significance and associated $95 \%$ confidence intervals are reported. Confidence limits are bottom and top coded in $[0.95,1.05]$ to enhance readability. 
Figure A7: Estimates of effects of exposure to school shootings on outcomes with placebo treatment assigned to individuals 20-26 years old at the time of the shooting incident

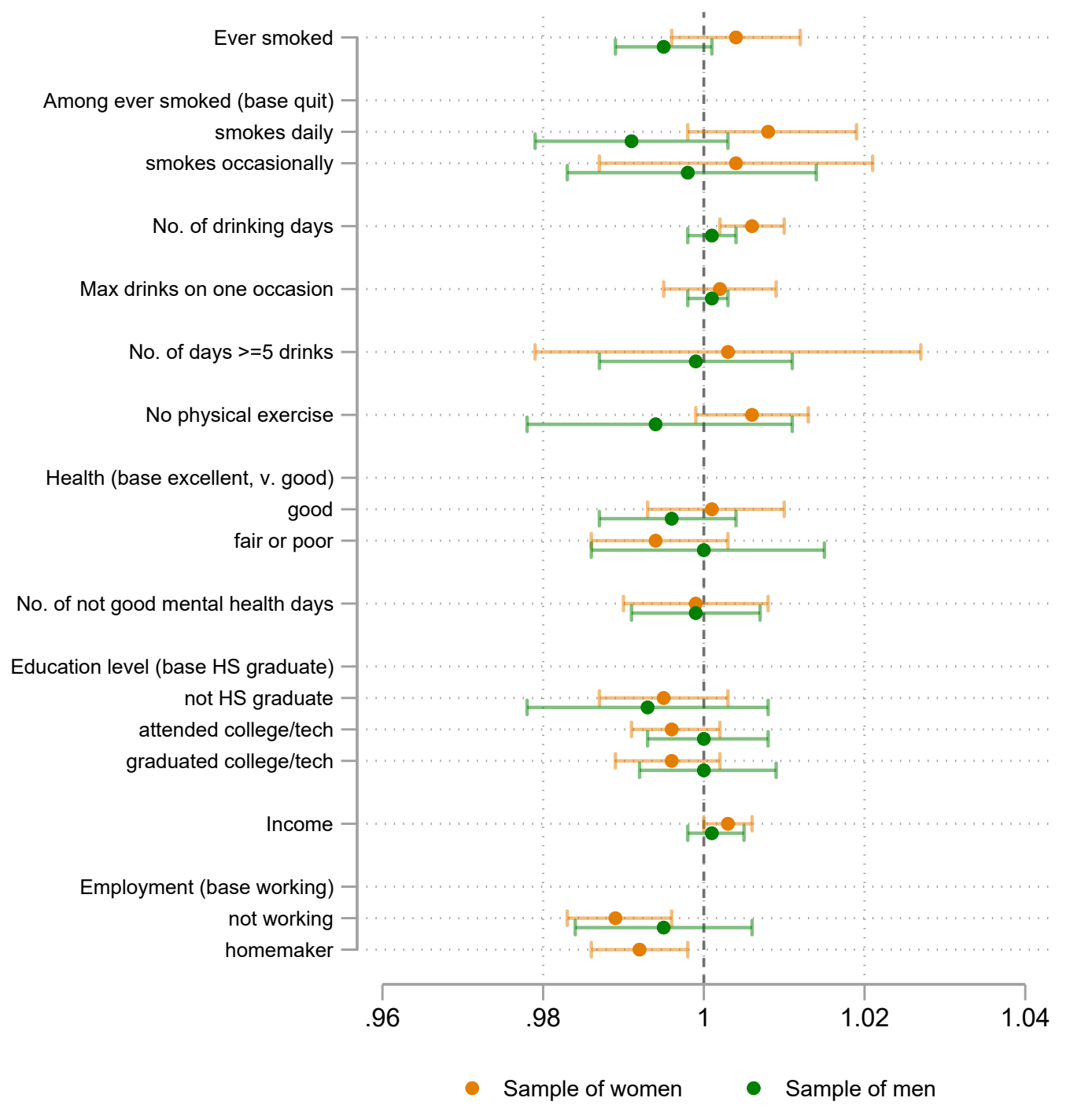

Note: The sample consists of individuals ages 28-37 years old living in 1402 counties from 2003-2012 BRFSS. Covariates include indicators for age, race and ethnicity, county and year, and duration. Exponentiated coefficients along with cluster-adjusted p-values for statistical significance and associated $95 \%$ confidence intervals are reported. Confidence limits are bottom and top coded in $[0.95,1.05]$ to enhance readability. 